\title{
PUBLICACIONES SOBRE FILOLOGÍA GRIEGA EN ESPAÑA (2009)
}

\author{
HELENA RodRíGuez SOMOLINOS \\ CCHS. CISC. Madrid \\ helena.rsomolinos@cchs.csic.es
}

\section{RESUMEN}

Bibliografía relativa a Filología Griega publicada en España en 2009.

Palabras Clave: Filología Griega; Bibliografía: España

\section{ABSTRACT}

Bibliography concerning Greek Philology published in Spain in 2009.

KEY WORDS: Greek Philology; Bibliography: Spain

\section{ORGANIZACIÓN}

1. Actas de congresos. Homenajes. Volúmenes colectivos

2. AUtORES ANTIGUOS. EDICIONES, TRADUCCIONES Y ESTUdIOS

3. Historia DE LA LITERATURA

4. LingüísticA GRIEGA. MÉtricA

5. MicenOlOGíA

6. EPigrafía. PAPIrología. Numismática

7. HISTORIA DE LOS TEXTOS

8. Historia. Cultura. Sociedad

9. Religión. Mitología

10. CRistianismo

11. Filosofía. Ciencia

12. Pervivencia. Humanismo. Historia de la Filología

13. DicCionARIOS. REPERTORIOS. OtROS INSTRUMENTOS

14. DidÁcticA 


\section{REVISTAS}

AEA

$A E F$

$A F-S G L$

$A M$

$A M-E$

$\mathrm{AuOr}$

Cal.Ren.

CCO

\section{CFCG}

CFCL

$E B$

EC

EClás.

EH

ELEA

Emerita

Epos

Faventia

$F N$

FI

Fortunatae

Gallaecia

Gerión

Habis
Archivo Español de Arqueología. Madrid, CSIC, Centro de Estudios Históricos. Dpto. de Arqueología y Prehistoria.

Anuario de Estudios Filológicos. Cáceres. Universidad de Extremadura. Facultad deFilosofía y Letras.

Anuari de Filologia. Secció D. Studia Graeca et Latina. Universitat de Barcelona. Facultat de Filologia.

Analecta Malacitana. Universidad de Málaga. Facultad de Filosofía y Letras. Sección de Filología.

Analecta Malacitana Electrónica. Universidad de Málaga. Facultad de Filosofía y Letras. Sección de Filología. http://www.anmal.uma.es/

Aula Orientalis. Revista de Estudios del Próximo Oriente Antiguo. Institut Interuniversitari d'Estudis del Pròximo Orient Antic. Sabadell (Barcelona). Editorial Ausa.

Calamus Renascens. Revista de Humanismo y tradición clásica. Alcañiz - Cádiz, Instituto de Estudios Humanísticos, Instituto de Estudios Turolenses, Universidad de Cádiz.

Collectanea Christiana Orientalia. Universidad de Córdoba. Faculta de Filosofía y Letras.

Cuadernos de Filología Clásica. Estudios Griegos e Indoeuropeos. Universidad Complutense de Madrid. Facultad de Filología.

Cuadernos de Filología Clásica. Estudios Latinos. Universidad Complutense de Madrid. Facultad de Filología.

Estudios Bíblicos. Madrid. C.S.I.C. Patronato Menéndez Pelayo. Instituto Francisco Suárez.

Exemplaria Classica. Departamento de Filologías Integradas. Facultad de $\mathrm{Hu}-$ manidades. Universidad de Huelva.

Estudios Clásicos. Madrid, Sociedad Española de Estudios Clásicos.

Estudios Humanísticos. Filología. Universidad de León. Facultad de Filosofía y Letras.

Estudios de Lenguas y Epigrafía Antiguas. Valencia. Real Academia de Cultura Valenciana.

Emerita. Revista de Lingüística y Filología Clásica. Madrid. C.S.I.C. Centro de Ciencias Humanas y Sociales. Instituto de Lenguas y Culturas del Mediterráneo y Oriente Próximo.

Epos. Revista de Filología. Madrid. Universidad Nacional de Educación a Distancia. Facultad de Filología.

Faventia. Universitat Autònoma de Barcelona. Facultat de Lletres. Dpto. de Filología Clásica.

Filología Neotestamentaria. Universidad de Córdoba. Facultad de Filosofía y Letras.

Florentia Iliberritana. Revista de Estudios de Antigüedad Clásica. Universidad de Granada.

Fortunatae. Revista canaria de filología, cultura y humanidades clásicas. Universidad de la Laguna. Departamento de Filología Clásica y Arabe.

Gallaecia. Universidad de Santiago de Compostela. Departamento de Historia I. Gerión. Universidad Complutense de Madrid. Departamento de Historia Antigua. Habis. Universidad de Sevilla. 
HAnt.

Hispania Antiqua. Revista de Historia Antigua. Universidad de Valladolid. Departamento de Historia Antigua.

Helmantica Helmantica. Revista de Filología Clásica y Hebrea. Universidad Pontificia de Salamanca.

Iberia Iberia. Revista de la Antigüedad. Universidad de La Rioja.

'Ilu 'Ilu. Revista de Ciencias de las Religiones. Universidad Complutense de Madrid. Instituto Universitario de Ciencias de las Religiones.

Interlingüística Interlingüística Revista de la Asociación de Jóvenes Lingüistas. Universitat de Girona. Facultat de Lletres.

Ítaca Ítaca. Quaderns Catalans de Cultura Clàsica. Barcelona. Institut d' Estudis Catalans.

Logo Logo. Revista de Retórica y Teoría de la Comunicación. Salamanca. Asociación Española de Estudios Sobre Lengua, Pensamiento y Cultura Clásica.

Lucentum Lucentum. Anales de Prehistoria, Arqueología e Historia Antigua. Universidad de Alicante.

MHNH Revista internacional de investigación sobre Magia y Astrología antiguas. Málaga, Centro de Ediciones de la Diputación de Málaga.

Minerva Minerva. Revista de Filología Clásica. Universidad de Valladolid. Departamento de Filología Clásica.

Myrtia Myrtia. Universidad de Murcia.

Palaeohispanica Palaeohispanica. Revista sobre lenguas y culturas de la Hispania Antigua. Zaragoza. Institución Fernando el Católico.

Paremia Paremia. Boletín de Investigaciones Paremiológicas. Madrid. Asociación Cultural Independiente (Sigüenza) - Universidad Complutense. Sersa Ediciones.

Ph.Canar. Philologica Canariensia. Universidad de Las Palmas de Gran Canaria. Facultad de Filología.

Polis Polis. Revista de ideas y formas políticas de la Antigüedad Clásica. Universidad de Alcalá de Henares.

R.S.E.L. Revista Española de Lingüística. Organo de la Sociedad Española de Lingüística. Madrid, Editorial Gredos.

Res Publica Litterarum Res Publica Litterarum. Documentos de trabajo del Grupo de Investigación Nómos. Universidad Carlos III de Madrid. Instituto de Estudios Clásicos sobre la Sociedad y la Política «Lucio Anneo Séneca».

SPhV Studia Philologica Valentina. Universidad de Valencia.

Veleia Veleia. Revista de Prehistoria, Historia Antigua, Arqueología y Filología Clásica. Vitoria. Universidad del País Vasco. Instituto de Ciencias de la Antigüedad.

Zephyrus Zephyrus. Revista de Prehistoria e Historia Antigua. Universidad de Salamanca.

\section{Actas de congresos. Homenajes. Volúmenes colectivos}

AA.VV.: Mundos imaginarios en la geografía de la Antigüedad. Madrid, Universidad de Salamanca, 2009 (= Studia Historica. Historia Antigua 27).

Arcos Pereira, T. - Fernández López, J. - Moya, F. (eds.): Pectora mulcet. Estudios de retórica y oratoria latinas. 2 vols. Logroño, Instituto de Estudios Riojanos, 2009 (= Pectora mulcet). 
Benoit, C. et aliI (EDS.): Escrituras del amor y del erotismo. Homenaje a Dolores Jiménez Plaza. Quaderns de Filologia, Anejo 65. València, Universitat de València, 2009 (= Escrituras del amor y del erotismo).

Candau Morón, J.M. - González Ponce, F.J. - Chávez Reino, A.L. (CoORds.): Libyae lustrare extrema. Realidad y literatura en la visión grecorromana de África. Homenaje al prof. Jehan Desanges. Sevilla, Universidad, 2009 (= Libyae lustrare extrema).

ChaparRo Gómez, C. et ali (EDS.): Nulla dies sine linea. Humanistas extremeños: de la fama al olvido. Cáceres, Universidad de Extremadura, 2009 (= Nulla dies sine linea).

CID LÓPEZ, R.M. (ED.): Madres y maternidades. Construcciones culturales en la civilización clásica. Oviedo, KRK, 2009 (= Madres y maternidades).

Conde Parrado, P.P. - Velázquez, I. (eds.): La filología latina. Mil años más. 3 vols. Madrid, Instituto Castellano y Leonés de la Lengua - SELAT, 2009 (= La filología latina. Mil años más).

García Romero, F. - Hernández García, B. (eds.): De Homero a Virgilio. El asombroso mundo de las lenguas griega y latina. Madrid, Sociedad Española de Estudios Clásicos, 2009 (= De Homero a Virgilio).

García Soler, M. J. (ED.): El humor (y los humores) en el mundo antiguo. Amsterdam - las Palmas, Hakkert, 2009.

González Castro, J.F. - Siles Ruiz, J. - Villa Polo, J. De la - Hinojo Andrés, G. - Almela Lumbreras, M.Á. - CañIZares Ferriz, P. (COORDS.): Perfiles de Grecia y Roma. Actas del XII Congreso Español de Estudios Clásicos (Valencia, 22-26 de Octubre de 2007). Madrid, Sociedad Española de Estudios Clásicos, 2009 (= Perfiles de Grecia y Roma).

González Salinero, R. - Ortega Monasterio, M.T. (EDS.): Fuentes clásicas en el judaísmo: de Sophia a Hokmah. Madrid, Signifer, 2009 (= Fuentes clásicas en el judaísmo).

LÓPEZ, A. - PociÑA, A. (EDS.): En recuerdo de Beatriz Rabaza. Comedias, tragedias y leyendas grecorromanas en el teatro del siglo XX. Granada, Universidad, 2009 (= En recuerdo de Beatriz Rabaza).

Martínez Fernández, A. (ED.): Estudios de epigrafía griega. Santa Cruz de Tenerife, Universidad de La Laguna, 2009 (= Estudios de epigrafía griega).

Martino, F. De - Morenilla, C. (EDS.): Teatro y sociedad en la antigüedad clásica. Leg timación e institucionalización política de la violencia. Valencia - Bari, Levante, 2009 (= Teatro y sociedad en la antigüedad clásica).

MuÑoz GarCía de ItURRoSPe, M.T.: Antiguos y modernos. Presencias clásicas de la Antigüedad al siglo XXI. Ponencias presentadas en las Jornadas celebradas en la Facultad de Letras de la Universidad del País Vasco-Euskal Herriko Unibertsitatea entre los días 5 y 7 de mayo de 2008. Bilbao, Universidad del País Vasco, 2009 (= Antiguos y modernos).

PAdorno, E. - SANTANA Henríquez, G. (EDS.): Omnia vincit amor. Consideraciones sobre el amor en la literatura universal. Madrid - Arucas, Ediciones Clásicas - Excmo. Ayuntamiento de Arucas - Fundación Canaria Mapfre Guanarteme, 2009 (= Omnia vincit amor).

Ramos JuRADo, E.A. (ED.): Cuatro estudios sobre exégesis mítica, mitografía y novela griegas. Zaragoza, Pórtico, 2009 (= Cuatro estudios).

SANCHO Rocher, L. (COORD.): Filosofía y democracia en la Grecia antigua. Zaragoza, Prensas Universitarias de Zaragoza, 2009 (= Filosofía y democracia en la Grecia antigua).

Sanz Morales, M - Librán Moreno, M. (EDS.): Verae lectiones. Estudios de crítica textual y edición de textos griegos. Huelva, Universidad, 2009 (= Verae Lectiones).

VAlCÁRCel MARTínez, V. (ED.): Las biografías griega y latina como género literario. De la antigüedad al Renacimiento. Algunas calas (= Las biografías griega y latina). Bilbao, Universidad del País Vasco, 2009.

Zamora Calvo, J.M. (ED.): La amistad en la filosofía antigua. Madrid, Universidad Autónoma, 2009 (= La amistad en la filosofía antigua). 


\section{Autores ANTIGUOS. Ediciones, traducCIONES y ESTUdios}

\section{Achilles Tatius}

FERNÁNDEZ-GARrido, R.: «Los sueños en la novela griega: Aquiles Tacio», Habis 40, 2009, 205-214.

REDONDO, J.: «À propos de l'érotisme dans le roman grec ancien. Le cas d'Achille Tatius», Escrituras del amor y del erotismo 237-246.

\section{Aelianus}

GARCía VAldÉs, M.: «Editar a Eliano: problemas que plantea», Verae lectiones 227-266.

\section{Aechines}

HERNÁNDEZ MuÑoZ, F.G.: «Aeschinea», Emerita 77, 2009, 247-269.

\section{Aeschylus}

BuzÓN, R.P. - ToRres, D.: «Representaciones del poder en el lenguaje del mito: Orestía de Esquilo y Las Moscas de J.P. Sartre», En recuerdo de Beatriz Rabaza 137-144.

EsQuilo: Agamenón. Introducción, traducción y notas de A. Martínez Díez. Madrid, Ediciones Clásicas, 2009.

EsQuilo: Prometeo encadenado. Traducción de R. Irigoyen. Barcelona, Nuevas Ediciones de Bolsillo, 2009.

Fialho Zambujo, M.D.: «Eros y violencia en Las suplicantes de Esquilo», Teatro y sociedad en la antigüedad clásica 185-194.

GARCía PÉREZ, D.: «Prometeo encadenado: el conflicto entre política y religión», Teatro y sociedad en la antigüedad clásica 195-210.

Garvie, A.F.: «Textual problems in Aeschylus' Persae», Verae lectiones 5-18.

Gil FernÁndez, J.: «Aeschylus, Eumenides 770», CFCG 19, 2009, 63-64.

Hernán-PÉrez Guijarro, P.: «Darío, Clitemestra y Polidoro, personajes fantasma de la tragedia griega con algo que decir», Fortunatae 20, 2009, 31-48.

Librán Moreno, M.: «Sermo amatorius en A.Th.686-688, 692-694, 718», CFCG 19, 2009, 89-101.

Pòrtulas Ambrós, J.: «Le ragioni delle Danaidi», Teatro y sociedad en la antigüedad clásica 271-304.

Pyplacz, J.: «Los elementos cómicos en la Orestía de Esquilo», CFCG 19, 2009, 103-114.

Santana Villaverde, J. - García Hoz, R.: Esquilo. El poeta trágico más grande de todos los tiempos. Valladolid, Fancy Ediciones, 2009.

SiLva Sousa, M.F.: «Conflicto de generaciones en la casa de los atridas. La versión de Esquilo de una vieja tradición», Teatro y sociedad en la antigüedad clásica 355-372.

Villa Polo, J. DE La: «Syntax and textual criticism: aspect in Aeschylus' Persae», Verae lectiones 19-32. 


\section{Aesopus et Aesopica}

CASCón Dorado, A.: «El ratón de campo y el ratón de ciudad: historia y sentido de una fábula», AF-SGL 25/26, 2003/2004, 87-105.

IRIGOYEN, R.: Fábulas de Grecia. Ilustraciones de P. Blanqart. Barcelona, Oniro, 2009.

\section{Agatharchides}

Albaladejo Vivero, M.: «Acerca de las fuentes empleadas por Agatárquides en su Sobre el mar Eritreo», Libyae lustrare extrema 305-318.

\section{Anacreontea}

GIANGRANDE, G.: «Sobre Anacreontea XIV 18», Myrtia 23, 2008, 455-456.

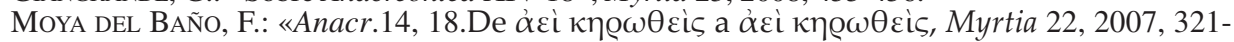
326.

\section{Anonymus}

SANCho Royo, A.: «Algunas consideraciones en relación con el tratado Sobre las figuras del discurso del anónimo XXIV», Habis 40, 2009, 229-238.

\section{Anthologia Graeca}

AA.VV.: La corona. Colección de epigramas eróticos griegos tomados del libro V de la Antología Palatina. Traducción de M. Á. Márquez Guerrero. Iluminados por J. Alcaíns. Cáceres, Javier Martín Santos Editor, 2009.

\section{Antipho}

RAMÓn PALERM, V.: «Antifonte y Michel Onfray», Perfiles de Grecia y Roma 583-590.

\section{Aphthonius}

Arcos Pereira, T. - CuYÁs de Torres, M.E.: «La enseñanza de la Retórica en los Scholia in Aphthonii progymnasmata de Juan de Mal Lara», Cal.Ren.8, 2007, 25-34.

\section{Apio}

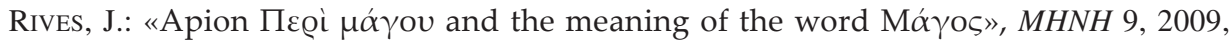
121-134. 


\section{Apollonius Rhodius}

DuRBEC, Y.: «Several deaths in Apollonius Rhodius Argonautica», Myrtia 23, 2008, 53-74.

\section{Appianus}

Gómez Espelosín, J.: «Contradicciones y conflictos de identidad en Apiano», Gerión 27(1), 2009, 231250.

\section{Archimedes}

ARQUÍMEDES: Tratados, II: Sobre las líneas espirales. Sobre el equilibrio de las figuras planas. Arenario. Cuadratura de la parábola. Sobre los cuerpos flotantes. Stomachion. Método, Libro de los lemas. Problema de los bueyes. Fragmentos. Introducciones, traducción y notas de P. Ortiz García. Madrid, Gredos, 2009.

CARRIón LóPEZ, P.: «La medida del círculo de Arquímedes: figura y texto de la proposición 1», CFCG 19, 2009, 65-88.

\section{Aristeas epicus}

BernabÉ, A.: «Un extraño viajero: Aristeas de Proconeso», en N. Morère Molinero (ed.), Viajes en el Mediterráneo antiguo. Madrid, Editorial Centro de Estudios Ramón Areces - Universidad de Sevilla, 2009, 39-48.

\section{Aristophanes}

ARISTÓFANES: Las asambleístas. Introducción, traducción y notas de C. Fernández. Barcelona, Losada, 2009.

ARISTÓFANES: Las aves. Introducción, traducción y notas de J.J. Viana. Madrid, Ediciones Clásicas, 2009.

ARISTÓFANES: Las avispas. Introducción, traducción y notas de J.J. Viana. Madrid, Ediciones Clásicas, 2009.

JERÓNIMO BUIS, E.: «Fragmentos de un discurso jurídico: la descontextualización del léxico judicial y su eficacia cómica en Comensales de Aristófanes», Emerita 77, 2009, 79-108.

LABIANO Ilundain, J.M.: «Notas sobre un fragmento aristofánico», Teatro y sociedad en la antigüedad clásica 211-226.

LóPEZ EIRE, A.: «La retoricidad del lenguaje y el contraste cómico en la comedia aristofánica», $E l$ humor (y los humores) en el mundo antiguo 7-42.

MAMOLAR SÁNCHEZ, I.: «Humor y puesta en escena en la comedia de Aristófanes», El humor (y los humores) en el mundo antiguo 95-112.

PagnI, S.: «Nota ad Aristoph., Plut.1011», EC 13, 2009, 3-10.

RodríGUEZ FERNÁNDEZ, G.: «Sueño y humor en Aristófanes», El humor (y los humores) en el mundo antiguo 113-132.

Santana HenRíquez, G.: «Amor, sexo y parodia en el teatro griego antiguo: el caso de Aristófanes», Omnia vincit amor 239-272. 


\section{Aristoteles}

Aristóteles: Poética. Edición trilingüe de V. García Yebra. Madrid, Gredos, 2009.

ARISTòTIL: Ėtica a Nicòmac. Versió de Brunetto Latini. Traducció valenciana de G. de Copons. Edició i pròlec de F. Bens. Introducció de M. Aroca. Valencia, L'Oronella, 2009.

ARISTÓteles: Ética a Nicómaco. Traducción de S. Rus Rufino. Madrid, Tecnos, 2009.

AubenQue, P.: «Amitié et communauté chez Aristote», La amistad en la filosofía antigua 113-120.

BAdRINEs Passani, F.: Presència de la filosofia aristotèlica en l'obra de C.S. Lewis. Barcelona, Universidad, 2009.

Besso, G. - Guagliumi, B. - Pezzoli, F.: «Un' edizione italiana commentata della Politica di Aristotele: problemi de traduzione e di critica testuale», Verae lectiones 95-126.

Blasina, A.: «'Rubare e `commettere furti sacrileghi in Aristotele: Retorica I, 1363b 27-33», AF-SGL 25/26, 2003/2004, 79-86.

Dareste de la Chavanne, R.: La science du droit en Grèce. Platon, Aristote, Théophraste. Pamplona, Analecta, 2009.

GonzÁlez Cruz, I.: El libro perdido de Aristóteles. Estudio de la poética. Valencia, Universidad Politécnica, 2009.

Gouguenheim, S.: Aristóteles y el Islam. Las raíces griegas de la Europa cristiana. Traducción de A. Escartín. Madrid, Gredos, 2009.

López BARJA De Quiroga, P.M.: «Aristóteles: El gobierno de los mejores», Filosofía y democracia en la Grecia antigua 199-228.

VAllejo CAmpos, Á: «Éros y philía en Platón y Aristóteles», La amistad en la filosofía antigua 63-78.

\section{Aristoxenus et Aristoxenica}

Hefestion - Aristoxeno - Ptolomeo: Hefestion: Métrica griega; Aristoxeno: Harmónica - rítmica; Ptolomeo: Harmónica. Introducciones, traducciones y notas de J. Urrea Méndez, F.J. Pérez Cartagena y P. Redondo Reyes. Madrid, Gredos, 2009.

\section{Artemidorus Daldianus}

RodríGuez FERNÁNDEZ, G.: «Sueño e intervención divina en la obra de Artemidoro», Perfiles de Grecia y Roma 601-610.

\section{Artemidorus Ephesius}

Ruiz Acevedo, J.M. - Campos Carrasco, J.M.: «El litoral onubense y algarveño en el `Papiro de Artemidoro : una nueva interpretación», Habis 40, 2009, 89-108.

\section{Athenaeus}

Jufresa Muñoz, M.: «El banquete de Ateneo, un espacio intercultural», AF-SGL 25/26, 2003/2004, 233-240. 


\section{Basilius Caesariensis}

NotARio PACHeCo, F.: «La integración de la cultura clásica pagana en el cristianismo desde la perspectiva de Basilio de Cesarea», en G. Bravo Castañeda - R. González Salinero (coords.), Formas de integración en el mundo romano. Actas del VI Coloquio de la Asociación Interdisciplinar de Estudios Romanos, Madrid, Signifer, 2009, 361-372.

\section{Biblia Graeca}

AasgaArd, R.: La infancia de Jesús. Texto biblingüe del Evangelio apócrifo del pseudo Tomás. Traducción de F.J. Molina de la Torre. Salamanca, Sígueme, 2009.

Álvarez Cineira, D.: Pablo y el imperio romano. Madrid, Sígueme, 2009.

AмICI, R.: «Principi e norme di non estraneità al mondo nelle lettere a Timoteo e a Tito», EB 67, 2009, 445-470.

Amphoux, C.: «Le canon du Nouveau Testament avant le IVe. siècle», FN 21(41), 2008, 9-25.

ÁnGEL EsPINós, J.: «El códice Complutensis Graecus 22: su destrucción y posterior recuperación», Perfiles de Grecia y Roma 177-184.

Barriocanal GómEZ, J.L.: «Jesús como nuevo Moisés en el evangelio de Juan», EB 67, 2009, 417444.

BERMEJo Rubio, F.: «Hipótesis sobre el Evangelio de Judas (I): los problemas hermenéuticos de un nuevo apócrifo», $E B$ 67, 2009, 471-504.

BERMEJo RuBio, F.: «Hipótesis sobre el Evangelio de Judas (II): ¿una reductio ad absurdum de la soteriología de la Gran Iglesia?», EB 67, 2009, 613-651.

CAstillo, A.L. - Fierro, G.: Ester, Judit, Rut, Tobías. Apócrifos del Antiguo Testamento. Estella, Verbo Divino, 2009.

Castillo, A.L. - Fierro, G.: Ester, Judit, Rut, Tobías. Apócrifos del Antiguo Testamento. 1 archivo de Internet. Estella, Verbo Divino, 2009.

DANOVE, P.: «Christological implications of the three-fold interpretation of verbs of transference», $F N$ 21(41), 2008, 27-44.

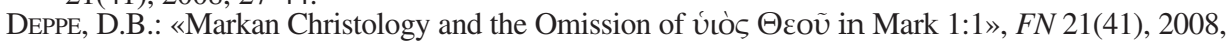
45-64.

FRADEJAS LeBRERO, J.: Los evangelios apócrifos en la literatura española. 1 archivo de Internet. Madrid, Biblioteca de Autores Cristianos, 2009.

GonzÁlez GonZÁlez, E.: Imitando a Rebeca. Modelos de feminidad para cristianas en el Antiguo Testamento (siglos II al IV). Oviedo, KRK, 2009.

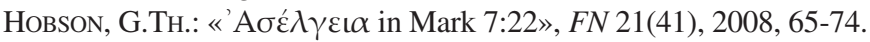

IвBA, G.: «Marco 1, 12-13 alla luce della letteratura giudaica pre-rabbinica», EB 67, 2009, 257-272.

Los evangelios apócrifos. Edición de A. Santos Otero. Madrid, Biblioteca de Autores Cristianos, 2009.

LUCK, G.: «Conjectural emendation in the greek New Testament», Verae lectiones 169-202.

MArTínez, A.E.: «Análisis composicional de Mateo 1,1-17: estructura argumentativa de la geneaología cristológica mateana», EB 67, 2009, 583-611.

Martorell, E.: Cartas de Juan y Judas. Madrid, Publicaciones EMI, 2009.

Montes Peral, L.Á.: «A la búsqueda de identidades: Santiago el Zebedeo, Santiago el de Alfeo, Santiago de Nazaret», $E B$ 67, 2009, 111-160.

NIESSEN, F.: «New testament translations from the Cairo Genizah», CCO 6, 2009, 201-222.

Pasala, S.: «The `Drama of the Messiah in Mattew 8-9: A Study from a Communicative Perspective», $E B$ 67, 2009, 395-416.

PEDE, E. DI: «Jérémie `prophète dans LXX et dans le TM», EB 67, 2009, 101-110. 
Peláez del Rosal, J. - Padilla, C.: «Espacio, tiempo y adversidad en los relatos de milagro del Evangelio de Marcos y de la Vida de Apolonio de Tiana, de Flavio Filóstrato», Fortunatae 20, 2009, 101-126.

PIÑERO, A. (ED.): Todos los Evangelios: canónicos y apócrifos. Madrid, Edaf, 2009.

PITTA, A.: «La Scrittura nelle 5 `Hauptbriefe di Paolo », EB 67, 2009, 273-302.

Ramis Darder, F.: Hechos de los Apóstoles. Estella, Verbo Divino, 2009.

RiUs-CAMPS, J. - READ-HEIMERDINGER, J.: «The variant readings of the Western Text of the Acts of the Apostles (XX) (Acts 13:44-52)», FN 21(41), 2008, 139-146.

URBÁN FERNÁNDEZ, A.: «Bezae codex cantabrigiensis (D): intercambios vocálicos en el texto griego de Juan», CCO 6, 2009, 375-403.

Uribe UlloA, P.: «Syneídesis en la Biblia Griega y mada' en la Biblia Hebrea. Implicaciones para una valoración del término `conciencia al interior del Antiguo Testamento, Moralia 32-121, 2009, 7-17.

VARgas MachucA, A.: «Concordias, Harmonías y sinopsis de los Evangelios. II: desde Huck-Lietzmann (1906-1936) a K. Aland (1964-2007)», EB 67, 2009, 9-84.

WatT, J. vAN DER - CARAGOUnIS, Chr.C.: «A grammatical analysis of John 1,1», FN 21(41), 2008, 91-138.

Whiteley, I.M.: «Cataphora and lack of clarity in the Book of Revelation», FN 21(41), 2008, 75-90.

\section{Callimachus}

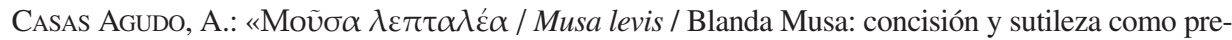
supuesto poético elegíaco desde Calímaco al Renacimiento», FI 20, 2009, 39-77.

Callinicus monachus

CALINICO: Vida de Hipacio. Introducción, traduccion y notas de R. Teja. Madrid, Trotta, 2009.

\section{Chalcidius}

Mir SABATÉ, F.: «La teoría de la visión en el Comentario al Timeo de Calcidio», AM-E 27, 2009, 317.

\section{Charito}

GÄRTNER, T.: «Vier Konjekturen zu griechischen Romanen», EC 13, 2009, 119-122.

SAnz Morales, M.: «Testimonio de los papiros y tradición medieval: (una versión diferente de la novela de Caritón?», Verae lectiones 203-226.

SAnz Morales, M.: «Conjeturas al texto de Caritón de Afrodisias, libros 5-8», EC 13, 2009, 95-118.

\section{Clementina}

POUDERON, B.: «La novela clementina: presentación de un dossier», Myrtia 24, 2009, 143-163. 


\section{Demosthenes}

Leganés Moya, P.: «La transmisión del discurso Sobre la embajada fraudulenta de Demóstenes en los manuscritos españoles», Verae lectiones 127-142.

\section{Dio Chrysostomus}

Hubeñák, F.: «Hacia una basileia romana: el caso de Dion de Prusa», Polis 20, 2008, 73-87.

Ventrella, G.: «Dione di Prusa fu realmente esiliato? L'orazione tredicesima tra idealizzazione letteraria e reconstruzione storico-giuridica (con un'appendice di E. Amato)», Emerita 77, 2009, 33-56.

\section{Diogenes Laertius}

Aparicio Villalonga, C.: «Diógenes Laercio IV 7 y VI 60: la provocación de Friné frente a la contienda del sabio», Perfiles de Grecia y Roma 501-510.

DióGENES LAERCIO: Vidas de los más ilustres filósofos griegos. Introducción, traducción y notas de J. Ortiz y Sáinz. Biblioteca Gredos. Barcelona, RBA Coleccionables, 2009.

Grau i Guijarro, S.: La imatge del filòsof i de l'activitat filosòfica a la Grècia antiga. Anàlisi dels tòpics biogràfics presents a les Vides i doctrines dels filòsofs més il.lustres de Diògenes Laerci. Barcelona, PPU, 2009.

Pons Olivares, D.: «D.L.VI 93: Crates, `ciudadano de Diógenes . Una revisión del cosmopolitismo cínico», Perfiles de Grecia y Roma 575-582.

\section{Dionysius Periegeta}

Counillon, P.: «La Libye dans la Description de la Terre habitée de Denys d'Alexandrie», Libyae lustrare extrema 361-374.

\section{Dioscorides}

Ben Mrad, I.: «Les gloses botaniques andalouses sur le manuscrit de Paris de la traduction arabe de la Materia Medica de Dioscorides», Al-Qantara 30/2, 2009, 581-622.

GiangRANDE, G.: «Dioscórides, Sófocles y la púrpura: un problema literario», Habis 40, 2009, 167-170.

PAgès CebriÁn, J.: «La Gigantomaquia según Euforión de Calcis: el escolio D a Ilíada 8.479», Habis 40, 2009, 81-88.

PAGÈs CEBRIÁn,Euphorio J.: «La Gigantomaquia según Euforión de Calcis: el escolio D a Ilíada 8.479», Habis 40, 2009, 81-88.

\section{Euphorio}

PAGÈs CEBRIÁN, J.: «La Gigantomaquia según Euforión de Calcis: el escolio D a Ilíada 8.479», Habis 40, 2009, 81-88. 


\section{Euripides}

Blanco Mayor, J.M.: «Athena ex machina: disturbing serenity in the Exodos of Euripides' Suppliants», Myrtia 24, 2009, 61-73.

Brioso SÁNCHEZ, M.: «La carta trágica», Habis 40, 2009, 45-68.

CALDERÓN DORDA, E.: «La tradición indirecta en la crítica textual griega. El texto de Eurípides en Plutarco», Verae lectiones 33-56.

CAmpos Daroca, J.: «Las voces de la violencia: lectura de Hécuba», Teatro y sociedad en la antigüedad clásica 93-118.

EuRíPIDEs: Fenicias. Suplicantes. Heraclidas. Traducción de A. Pérez Jiménez. Madrid, Alianza Editorial, S.A.

EuRíPIDES: Las troyanas. Traducción de R. Irigoyen. Madrid, Teatro Español, 2009.

GALlARDO LóPEZ, M.D.: «La mitología clásica en dos maestros catalanes del siglo XX», La filología latina. Mil años más 1803-1813.

HERNÁN-PÉREZ GUIJARRo, P.: «Darío, Clitemestra y Polidoro, personajes fantasma de la tragedia griega con algo que decir», Fortunatae 20, 2009, 31-48.

LADRA, D.: «El hito de Las Troyanas, de Eurípides. Las mujeres en la tragedia griega», Primer acto. Cuadernos de investigación teatral 331, 2009, 84-87.

LÓPez Rodríguez, C. - CAMACHO Rojo, J.M.: «¿Quién condena a Ifigenia?», Teatro y sociedad en la antigüedad clásica 465-476.

Macías Otero, S.M.: «Los versos 1259-1273 de Hécuba de Eurípides. ¿Metamorfosis o metempsicosis?», Perfiles de Grecia y Roma 547-554.

Morenilla, C.: «Andrómaca y Helena. Sobre el amor en el oikos», Escrituras del amor y del erotismo 195-206.

PociÑa LóPEZ, A.J.: «Tradición y creación: de Alcestis de Eurípides a Alcesti de Corrado Alvaro», En recuerdo de Beatriz, Rabaza 523-528.

Redondo Moyano, E.: «El êthos de los violentos en las tragedias euripideas de tema troyano (I)», Teatro y sociedad en la antigüedad clásica 305-340.

RIBEIRO FERREIRA, J.: «No tiene importancia la vida del esclavo. La violencia y la guerra en Andrómaca y en Las suplicantes de Eurípides», Teatro y sociedad en la antigüedad clásica 341-354.

Salvador Ventura, F.J.: «Las tragedias de Eurípides mediante el cineasta griego M. Cacoyannis», En recuerdo de Beatriz Rabaza 595-606.

\section{Eutocius}

BEZZA, G.: «Intorno ai primi commentatori del Quadripartitum tolemaico: il commento ascritto ad Eutocio d'Ascalona», $M H N H$ 9, 2009, 265-271.

\section{Galenus}

GALENO: Sobre la utilidad de las partes del cuerpo humano en diecisiete libros. Estudio introductorio, bibliografía, sinopsis de libros y capítulos, traducción, notas y léxicos de M. Cerezo Magán. Madrid, Ediciones Clásicas, 2009.

Santana Henríquez, G.: «La terminología médica sobre los dolores de cabeza en Galeno», $\mathrm{Ph} . \mathrm{Ca}$ nar.14/15, 2008/2009, 279-296.

Vela TejadA, J.: «Koiné y aticismo en Galeno, «De antidotis»: datos para un estudio lingüístico», CFCG 19, 2009, 41-61. 


\section{Hanno}

GONZÁLEZ PONCE, F.J.: «Los huidizos gorilas de Hanón y la tradición helenística sobre la zoología fabulosa de la India», Libyae lustrare extrema 291-304.

\section{Heliodorus}

GÄRTNER, T.: «Vier Konjekturen zu griechischen Romanen», EC 13, 2009, 119-122.

\section{Hephaestio grammaticus}

Hefestion - ARISTOXeno - Ptolomeo: Hefestion: Métrica griega; Aristoxeno: Harmónica - rítmica; Ptolomeo: Harmónica. Introducciones, traducciones y notas de J. Urrea Méndez, F.J. Pérez Cartagena y P. Redondo Reyes. Madrid, Gredos, 2009.

\section{Heraclitus}

HERÁCLITO: Fragmentos e interpretaciones. Edición de J.L. Gallero y C.E. López. Madrid, Árdora, 2009.

\section{Heraclitus paradoxographus}

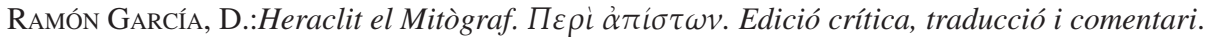
Tesis doctoral. Barcelona, Universitat Autònoma, 2009.

\section{Herodianus historicus}

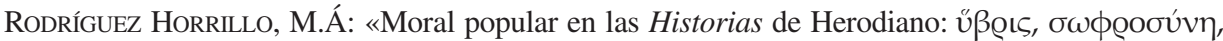

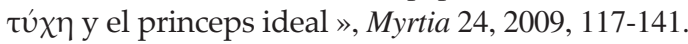

\section{Herodotus}

AlbuRquerque, P.: «Algumas consideraçôes em torno da construçâo de Tartessos em Heródoto (I, 163 e IV, 152)», Gerión 27(1), 2009, 91-125.

GómEz EsPelosín, F.J.: «Heródoto, Libia y la geografía de los confines», Libyae lustrare extrema 235252.

HERÒDOT: Història. Introducció, text revisat, traducció i notes de M. Balasch. Barcelona, Altaya, 2009. HERÒDOT: Història. Pròleg de J.F. Mira. Introducció, traducció i notes de R.J. Montañés. Barcelona, La Magrana, 2009.

Heródoto: La batalla de las Termópilas. Traducción de C. Schrader y J.J. Torres Esbarranch. Barcelona, RBA, 2009.

HERÓDOTO: Los nueve libros de la historia. Traducción del griego y sus notas por el P. Bartolomé Pou, S.J. ; con unas notas prologales de E.M. Aguilera. Barcelona, Iberia, 2009. 
JiMÉNEZ Delgado, J.M.: «Historias de Heródoto en el contexto minorasiático: la prosa historiográfica hitita», AurOr 27, 2009, 57-75.

RuIZ SÁNCHEZ, M.: «La mano cortada: cuentos de ladrones de Heródoto a nuestros días (I)», Myrtia 24, 2009, 239-272.

SimÔES RodRIGUES, N.: «Rodópis no país dos faráos: itinerário de uma hetera grega», $C F C G$ 19, 2009, 115-123.

\section{Hesiodus}

SÁNCHEZ DE LA TORRE, Á.: «La justicia, antes (sin) ciudad: los poemas de Hesíodo», Anales de la Real Academia de jurisprudencia y legislación 39, 2009, 119-130.

\section{Hippocrates et Corpus Hippocraticum}

Alonso GuARDo, A.: «Apuntes sobre el léxico ginecológico en el De mulierum affectibus del Corpus hippocraticum», La filología latina. Mil años más 117-136.

ÁNGEL Y ESPINÓs, J.: «Algunas consideraciones acerca de ciertos rasgos sintácticos en Epidemias V y VII. La subordinación temporal en el contexto de la lengua hipocrática», Minerva 22, 2009, 107-126.

Esteban Santos, A.: «Incisos dentro de las historias clínicas de Epid.V y VII: los distintos tipos de pasajes», CFCG 19, 2009, 125-139.

Pino CAMPOS, L.M.: «La polisemia de $\sigma \phi \cup \gamma \mu$ ó en el Corpus Hippocraticum (II)», Fortunatae 20, 2009, 127-138.

Ramón Palerm, V.: «Fórmulas de origen oral en el Corpus Hippocraticum», Myrtia 24, 2009, 29-49.

VINTRÓ CASTELls, E.: «Hipócrates y la teoría de los humores», El humor (y los humores) en el mundo antiguo 43-54.

\section{Homerus}

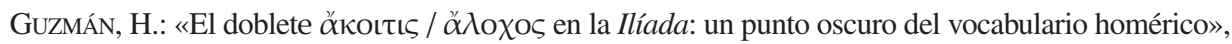
Myrtia 24, 2009, 15-27.

Homero: Ilíada. Edición de D. Plácido. Madrid, La Esfera de los Libros, 2009.

Homero: Ilíada. Traducción de F. Gutiérrez. Barcelona, Planeta, 2009.

Homero: Ilíada vol. III. Cantos X-XVII. Texto crítico, traducción y notas por L.M. Macía Aparicio. Madrid, Consejo Superior de Investigaciones Científicas, 2009.

Homero: Odisea. Versión y prólogo de C. García Gual. Ilustraciones de John Flaxman. Madrid, Alianza, 2009.

JONG, I.J.F. DE: «Un comentario narratológico sobre la Odisea: principios y problemas», EClás.135, 2009, 7-28.

LÓPEZ FÉrez, J.A.: «Presencia de la Odisea en ¿Por qué corres, Ulises? de Antonio Gala», Fortunatae 20, 2009, 49-70.

Montes Miralles, M.Y.: «Notas sobre la nemesis de los dioses iliádicos», Perfiles de Grecia y Roma 639-648.

ORTEGa CARMona, A.: «Homero: primeras representaciones griegas sobre el alma», Myrtia 23, 2008, 9-16.

Pòrtulas, J.: Introducció a la Ilíada. Homer, entre la història i la llegenda. Barcelona, Alpha, 2009. 
RodríGueZ Adrados, F.: «Sobre el sentido y orígenes de la Odisea», EClás.136, 2009, 57-70.

TORRes, J.: El aedo. Monólogo dramático sobre la Odisea. Madrid, Ediciones Clásicas, 2009.

\section{Hymni Homerici}

Fernández García, V.: «El Himno homérico a Deméter: una reinterpretación de la relación madre-hija a través del mito», Madres y maternidades 329-347.

Himnes homèrics. Traducció de M.R. Llabrés i Ripoll. Pollensa, Edicions del Salobre, 2009.

\section{Iosephus}

Hadas-Lebel, M.: Flavio Josefo. El judio de Roma. Barcelona, Herder, $2009^{2}$.

OSSANDÓN Widow, J.C.: «Flavio Josefo y los veintidós libros. Nuevas preguntas en torno a Contra Apionem I, 37-45», EB 67, 2009, 653-694.

\section{Iulianus}

Julià L'ApÒstaTA: El banquet dels Cesars. Introducció i traducció d'A. Martín. Edició bilingüe grec-catalá. Barcelona, Adesiara, 2009.

Redondo Moyano, E.: «Encomio de personajes femeninos: Elogio de la emperatriz Eusebia de Juliano el Apóstata», Antiguos y modernos 59-80.

Redondo Moyano, E.: «Humor y retórica: Antiochikós o Misopogon de Juliano», El humor (y los humores) en el mundo antiguo 55-94.

\section{Lucianus}

Luciano de Samosata: El bibliómano ignorante. Traducción de H. González Vaquerizo. Madrid, Errata Naturae, 2009.

SÁNCHEZ HeRnÁndEZ, J.P.: «Luciano de Samósata y la política griega del s. II d.C.: a propósito del Encomio de la Patria», CFCG 19, 2009, 163-181.

\section{Marcus Aurelius Antoninus}

BIRLey, A.R.: Marco Aurelio. Una biografía. Madrid, Gredos, 2009.

\section{Menander}

GRAMMATAS, TH.: «Menandre sur scene: l'experience neo-hellenique», CFCG 19, 2009, 141-149.

Konstan, D.: «The miser's daughter from Menander to George Bernard Shaw», En recuerdo de Beatriz Rabaza 277-290.

MACUA MARTíneZ, E.: «Humor y comicidad en el misántropo: la evolución del tipo desde el ámbito dramático (Menandro y Molière) hasta la narrativa (Villalonga, Moravia y Castellani)», El humor (y los humores) en el mundo antiguo 159-186. 
Macua Martínez, E.: Técnicas de caracterización en Menandro (Samia, Perikeiromene y Epitrépontes). Vitoria, Universidad del País Vasco, 2009.

\section{Origenes}

BLÁZquez MartíneZ, J.M.: «Orígenes y su legado al Mundo Antiguo y al Mundo Moderno», Gerión 27(1), 2009, 263-295.

\section{Orphica}

BernabÉ PAJARES, A.: «Problemas de edición de textos fragmentarios: el caso de los órficos», Verae lectiones 267-290.

\section{Ostanes}

FERNÁNDEZ GARCÍA, A.: «Ostanes, maestro alquímico», Perfiles de Grecia y Roma 731-744.

\section{Parmenides}

Panchenko, D.: «Parmenides, the Nile and the Circumnavigation of Africa by the Phoenicians», Libyae lustrare extrema 189-194.

\section{Pausanias}

SÁNCHEZ HERNÁNDEZ, J.P.: «Pausanias, la transformación del Oriente heleno y la crisis de la República Romana (Notas a Paus. VIII, 27, 1)», Myrtia 23, 2008, 121-134.

\section{Philo Iudaeus}

CAlabi, F.: «La filosofia greca in Filone di Alessandria», Fuentes clásicas en el judaísmo 3350.

Filón DE AlEJANDRÍA: Obras completas I. Edición dirigida por J.P. Martín. Madrid, Trotta, 2009.

Filón DE Alejandría: Obras completas V. Edición dirigida por J.P. Martín. Madrid, Trotta, 2009.

PEREA YéBENES, S.: «Los therapeutai judíos de Egipto, una singular «república religiosa» platónica (en el De vita contemplativa de Filón de Alejandría), y la tradición literaria griega pre y post filoniana», Fuentes clásicas en el judaísmo 51-86.

\section{Philodemus}

INDELLI, G.: «Le opere morali di Filodemo conservate nei Papiri Ercolanesi: un bilancio degli studi più recenti», Perfiles de Grecia y Roma 259-546. 


\section{Philostratus}

Peláez del Rosal, J. - Padilla, C.: «Espacio, tiempo y adversidad en los relatos de milagro del Evangelio de Marcos y de la Vida de Apolonio de Tiana, de Flavio Filóstrato», Fortunatae 20, 2009, 101-126.

\section{Photius}

PRIETO Domínguez, O.: «Epistulae et amphilochia patriarchae Photii: mezcla confusión de elementos en la constitutio textus de ambos corpora», Verae lectiones 291-320.

\section{Plato}

Arroyo Merino, M.: Platón. Dialéctica de las ideas, dialéctica de los actos. Tesis doctoral. Madrid, Universidad Nacional de Educación a Distancia, Facultad de Filosofía, 2009.

Bordoy FERNÁNDEZ, A.: «La cuestión del origen de la materia: análisis del comentario de Calcidio al concepto de materia en el Timeo de Platón», Perfiles de Grecia y Roma 511-520.

Dareste de la Chavanne, R.: La science du droit en Grèce. Platon, Aristote, Théophraste. Pamplona, Analecta, 2009.

ERnOULT, N.: «Maternité et rôle maternel dans les cités idéales de Platon», Madres y maternidades 93-112.

García SAntos, R.: Platón: De la aristocracia militar a la tiranía en el `Republica . Badajoz, Abecedario, 2008.

MAS, S.: «La crítica de Platón a la democracia: Paideía politiké», Filosofía y democracia en la Grecia antigua 161-198.

Mir SABATÉ, F.: «La teoría de la visión en el Comentario al Timeo de Calcidio», AM-E 27, 2009, 3-17.

Morilla Palacios, A.: «La Atlántida y Macondo: mito y utopía literaria», Studia Historica. Historia Antigua 27, 2009, 129-145.

NEY, H.O.: «Liens d'amitié et constitution de la cité chez Platon», La amistad en la filosofía antigua 93-112.

Plató: Cartes. Traducció de R. Garrigasait Colomés. Barcelona, Alpha, 2009.

Platón: La república. Edición de R.M. Mariño Sánchez-Elvira, S. Mar Torres y F. García Romero. Madrid, Akal, 2009.

RAMOS JURADO. E.A.: «Del antialegorismo de Platón al alegorismo de su entorno. Poesía y filosofía en Grecia en el siglo IV a.C.», Cuatro estudios 9-60.

Romeri, L.: «Plutarque et l' âme du monde de Platon», AF-SGL 25/26, 2003/2004, 315-333.

Ruiz YamuZA, E.: «El Fedro de Platón en manuscritos españoles. IV: el Matritensis 4569», Habis 40, 2009, 69-80.

TOMÁs GARCía, J.: Platón y el arte de su época. La controversia entre realidad y representación en el universo platónico. Madrid, Signifer, 2009.

VALENTE, S.: «Il ruolo di Timeo Sofista nella constitutio textus della Repubblica di Platone», Verae lectiones 67-94.

VALLEJo CAMPOS, Á: «Éros y philía en Platón y Aristóteles», La amistad en la filosofía antigua 63-78.

Wersinger, A.G.: «La `déclaration d'amour et les formules de la philia dans les dialogues de Platon», La amistad en la filosofía antigua 79-92.

\section{Plotinus}

Zamora CAlvo, J.M.: «La noción de amistad en Plotino», La amistad en la filosofía antigua 169-186. 


\section{Plutarchus}

CALDERÓn Dorda, E.: «La tradición indirecta en la crítica textual griega. El texto de Eurípides en Plutarco», Verae lectiones 33-56.

GARCíA LÓPEZ, J.: «Estructura formal y elementos religiosos en las Vidas de Plutarco: Pericles», Myrtia 23, 2008, 87-100.

Gómez CARDó, P.: «'Laconismo como virtud en la Atenas del s. V a.C.: a propósito de la Vida de Cimón de Plutarco», Myrtia 22, 2007, 69-81.

HERNÁNDEZ DE LA FuENTE, D.A.: «Entre Claudio y Clodio: fonética y política en la traducción de Plutarco, Luc.21, 1», CFCG 19, 2009, 29-39.

Medina Quintana, S.: «Madres y maternidades en Plutarco. Una valoración de textos seleccionados», Madres y maternidades 349-359.

PéreZ Vilatela, L.: «La superstición según Plutarco: del bárbaro a Santo Tomás», ELEA 9, 2009, 503-522.

Pérez Vilatela, L.: «Sol interior y eternidad en los Moralia de Plutarco: una nota», ELEA 9, 2009, 549-556.

PlutARCO: Consejos a los políticos para gobernar bien. Traducción de J. García López. Madrid, Siruela, 2009.

Plutarco: Consejos políticos. Sobre el exilio. Traducción de R. Caballero Sánchez. Madrid, Alianza, 2009.

Plutarco: Vidas paralelas VII. Demetrio. Antonio. Dión. Bruto. Arato. Artajerjes. Galba. Otón. Introducciones, traducciones y notas de J.P. Sánchez Hernández y M. González González. Madrid, Gredos, 2009.

Plutarco: Sobre el amor a las riquezas, seguido de 'Que no hay que pedir prestado a interés. Nota introductoria y traducción de F. Gutiérrez. Palma, José J. de Olañeta, 2009.

PlutARCO: Vidas semblantes. Versión aragonesa de las Vidas paralelas, patrocinada por Juan Fernández de Heredia. Edición, introdución y notas de A. Álvarez Rodríguez, 2 vols. Zaragoza, Prensas Universitarias, 2009.

RAMÓN PALERM, V.M.: «Plutarco y la biografía política en Grecia: aspectos de innovación en el género», Las biografías griega y latina 41-68.

Ramos Jurado, E.Á.: «Tropos y figuras en De Homero del Pseudo-Plutarco», Habis 40, 2009, 239-246.

Romeri, L.: «Plutarque et l' âme du monde de Platon», AF-SGL 25/26, 2003/2004, 315 333.

Ruiz Montero, C. - Jiménez, A.M.: «Mulierum virtutes» de Plutarco: aspectos de estructura y composición de la obra», Myrtia 23, 2008, 101-120.

VicenTE SÁNCHEZ, A.: «La composición de El banquete de los siete sabios: un relato epistolar», Fortunatae 20, 2009, 139-160.

Vicente SÁncheZ, A.: «Cartas reales y cartas en la literatura: Estudio a través de un tipo epistolar utilizado por Plutarco», Ph.Canar.14/15, 2008/2009, 49-376.

\section{Porphyrius Tyrius}

Ramos JuRAdo, E.A. et aliI (EDS.): Porfirio de Tiro, contra los cristianos. Recopilación de fragmentos, traducción, introducción y notas de E.A. Ramos Jurado y otros. Cádiz, Universidad, 2006. 


\section{Posidippus}

Calderón Dorda, E.A.: «Los Cantos sáficos del epigrama 55 A.-B. (P.Mil.Vogl. VIII 309, IX 1-6) de Posidipo», Myrtia 23, 2008, 75-86.

\section{Pratinas}

Redondo Reyes, P.: «Crítica poética y unidad temática en Prátinas, frs. 1 y 5 Page (I)», Myrtia $22,2007,35-58$.

Redondo Reyes, P.: «Crítica poética y unidad temática en Prátinas (II)», Myrtia 23, 2008, 2952.

\section{Ptolemaeus}

BEZZA, G.: «Intorno ai primi commentatori del Quadripartitum tolemaico: il commento ascritto ad Eutocio d'Ascalona», $M H N H$ 9, 2009, 265-271.

Gómez Aranda, M.: «La recepción del pensamiento de Claudio Ptolomeo en el judaísmo medieval», Fuentes clásicas en el judaísmo 189-212.

Hefestion - Aristoxeno - Ptolomeo: Hefestion: Métrica griega; Aristoxeno: Harmónica - rítmica; Ptolomeo: Harmónica. Introducciones, traducciones y notas de J. Urrea Méndez, F.J. Pérez Cartagena y P. Redondo Reyes. Madrid, Gredos, 2009.

Komorowska, J.: «Astrology, Ptolemy and technai stochastikai», MHNH 9, 2009, 129-140.

\section{Sappho}

Barrios Castro, M.J.: «Un fragmento ficticio de Safo en Ezra Pound: ¿pseudocita o monólogo dramático?», CFCG 19, 2009, 233-244.

SÁnchez Ortiz de Urbina, R.: Safo y sus discípulas. Poemas. Madrid, Ediciones del Oriente y del Mediterráneo, 2009.

Sánchez Ortiz de Urbina, R.: Safo y sus discípulas. Poemas. 1 archivo de Internet. Madrid, Ediciones del Oriente y del Mediterráneo, 2009.

\section{Serapio}

Denningmann, S.: «Die Datierung des Astrologen Serapion», MHNH 9, 2009, 159-174.

\section{Sophocles}

Bañuls Oller, J.V. . Morenilla Talens, C.: «Justicia y violencia en la tragedia de Sófocles», Teatro y sociedad en la antigüedad clásica 17-64.

Bañuls Oller, J.V. - CRespo Alcalá, P.: «'Los no rechazables dones de la áurea Afrodita en Sófocles», Escrituras del amor y del erotismo 39-51.

EnCinAs Reguero, M.C.: «La defensa retórica de la traición en el Áyax de Sófocles», Myrtia 22, 2007, 59-67. 
García FernándeZ, A.M.: «Hegel interpreta a Sófocles», en Res Publica Litterarum 2009.

Giangrande, G.: «Dioscórides, Sófocles y la púrpura: un problema literario», Habis 40, 2009, 167170.

GILABERT BARBERÀ, P.: «New York versus Tragedy and Oedipous: the legacy of Sophocles and the Sophists in Woody Allen's Crimes and misdemeanors», AF-SGL 25/26, 2003/2004, 179-193.

GonZÁLEZ GALVÁN, M.G.: «Observaciones sobre el enfrentamiento Electra-Clitemnestra en la Electra de Sófocles», Ph.Canar.12/13, 2006/2007, 347-352

HERRERAS, E.: «Antígona y la democracia deliberativa» Sistema. Revista de ciencias sociales 212, 2009, 87-102.

Martínez Pulet, J.M.: «Cuando el dolor quiebra cuerpo y voz: Sobre el Filoctetes de Sófocles», $A$ Parte Rei: revista de filosofía 61, 2009.

SANTAMaría, A.L.: Implicaciones éticas de la Antígona de Sófocles una reflexión sobre el pensamiento trágico griego. Madrid, Plaza y Valdés, 2009.

Sófocles: Antígona. Traducción de L. Gil Fernández. Barcelona, Nuevas Ediciones de Bolsillo, 2009.

Sófocles: Antígona. Electra. Traducción de V. López de Soto. Barcelona, Juventud, 2009.

Sófocles: Edipo Rey. Traducción de J. Cano Cuenca. Madrid, Cátedra, 2009.

Sófocles: Les dones de Traquis. Antigona. Text revisat i traducciò de C. Riba. Barcelona, Altaya, 2009.

SòFocles: Tragèdies tebanes : Antígona ; Ėdip rei ; Ėdip a Colonos. Traducció de C. Riba. Introducció de J.P.A. Gould. Barcelona, Edicions 62 - Alpha, 2009.

STEINER, G.: Antígonas. Una poética y filosofía de la lectura. Traducción de A.L. Bixio. Barcelona, Gedisa, 2009.

\section{Strabo}

Amela ValVerde, L.: «Mileto, Esquines y Pompeyo Magno», Helmantica 181, 2009, 7-14.

GONZÁLEZ SANTANA, M.: «El mito de la bárbara. La maternidad y las mujeres del noroeste hispánico en Estrabón», Madres y maternidades 361-372.

\section{Theocritus}

MonTes CAlA, J.G.: «El diálogo platónico y los modos de enunciación del idilio teocriteo», $C F C G$ 19, 2009, 151-162.

\section{Theophrastus}

Dareste de la Chavanne, R.: La science du droit en Grèce. Platon, Aristote, Théophraste. Pamplona, Analecta, 2009.

Giangrande, G.: «El Proemio de los Caracteres de Teofrasto», Myrtia 23, 2008, 451-454.

TEOFRAST: Caràcters. Traducció de J. Batalla i Costa. Tarragona, Obrador Edèndum, 2009.

\section{Thucydides}

Tucidides: Història de la guerra del Peloponès. Text revisat i traducció de J. Berenguer Amenós. Barcelona, Edicions 62 - Altaya, 2009. 


\section{Xenopho}

Jenofonte: Apología. Banquete. Recuerdos de Sócrates. Traducción de J.A. Caballero López. Madrid, Alianza, 2009.

JeNOFONTE - PSEUdo-JENOFONTE: Constitución de Esparta. Constitución de Atenas. Introducción, traducción, notas y comentario de P. Varona. Madrid, Cátedra, 2009.

Xenofont: Els deu mil (Anàbasi). Traducció de F.J. Cuartero i H. Lamela Badia. Barcelona, Alpha, 2009.

\section{HISTORIA DE LA LITERATURA}

AguirRe, M.: «Some Ghostly Appearances in Greece: Literary and Artistic Sources», Gerión 27(1), 2009, 179-189.

Antologia obituària dels filòsofs de la Grècia antiga a cura de S. Grau. Martorell, Adesiara, 2009.

BRIOSO SÁNCHEZ, M.: «Autor, narrador, lector y narratario en la novela griega antigua», Cuatro estudios 153-242.

Calvo Martínez, J.L.: Antología de poesía erótica griega. Madrid, Cátedra, 2009.

CARMona CEnTENo, D.: La epipólesis en la historiografía grecolatina. Tesis doctoral. Cáceres, Universidad de Extremadura, 2009.

Citti, V. - Pòrtulas, J. - SuÁrez de la Torre, E. - Vintró, E.: «Studies on Elegy and Iambus, de Carles Miralles: acte de presentació», AF-SGL 25/26, 2003/2004, 107-117.

DURÁn MAÑAS, M.: La literatura helenística e imperial. Características generales. 1 archivo de Internet. Liceus, Servicios de Gestión y Comunicación, 2009.

EnRILE ARRATE, J.P.: Arquitectura de espectáculo y puesta en escena en la Antigua Grecia. Madrid, Fundamentos, 2009.

FOWLER, R.L.: «Thoughts on Myth and Religion in Early Greek Historiography», Minerva 22, 2009, 21-39.

García Gual, C.: Prometeo. Mito y literatura. Madri, Fondo de Cultura Económica de España, 2009.

García Gual, C.: «Viajeros griegos. Viajes reales y fantásticos», en F. Calderón Quindós - P.J. Pérez López (coords.), Viajes, literatura y pensamiento, Valladolid, Universidad, 2009, 85-112.

García Molinos, A. - Pérez Benito, E.: «Voces del más allá: la necromancia en los Papiros Mágicos y en la novela griega», Perfiles de Grecia y Roma 613-620.

GARCíA RoMero, F.: «Alabanza y crítica del deporte en la literatura griega», Materiales para la historia del deporte 7, 2009, 9-22.

GARCíA SOLER, M.J.: «La gastronomía como recurso cómico en la literatura griega», El humor (y los humores) en el mundo antiguo 133-158.

HERNÁNDEZ BERnAL, J.: Crestomatía de los teatros griegos y romano. Murcia, Áglaya, 2009.

HERNÁNDEZ BERnAL, J.: Glosario del teatro griego y su contexto. Murcia, Áglaya, 2009.

HerReras MaldonAdo, E.: La aportación de la tragedia griega a la educación democrática. 1 CD-ROM. Valencia, Universidad, 2009.

Julián Gallego, J. - IRIARTE GoÑI, A.: «La tragedia ática: política y emotividad», Filosofía y democracia en la Grecia antigua 103-126.

Konstan, D.: «The miser's daughter from Menander to George Bernard Shaw», En recuerdo de Beatriz Rabaza 277-290.

LESKY, A.: Historia de la literatura griega I: De los comienzos a la polis griega. Prólogo de E. Crespo. Traducción de J.M. Díaz-Regañón López y B. Romero. 2 vols. Madrid, Gredos, 2009.

LEWIT, A.L.: «Trauerspiel y Tragedia griega: una comparación a partir del lugar de la culpa», A Parte Rei. Revista de filosofía 61, 2009. 
LÓPEZ-MuÑOZ, M.: «La retórica antigua en internet», Pectora mulcet 1323-1336.

MARTINO, F. DE: «All'ultimo sangue; Appendice iconografica», Teatro y sociedad en la antigüedad clásica 119-154.

Martos MonTIEL, J.F.: «Bibliotheca erotica graeca et latina. Erotismo y sexualidad en la Antigüedad clásica: ensayo de un repertorio bibliográfico (III. Clasificación temática, 5-7)», AM-E 26, 2009, 215-257.

Martos Montiel, J.F. - Fornieles Medina, M.F.: «Bibliotheca erotica graeca et latina. Erotismo y sexualidad en la Antigüedad clásica: ensayo de un repertorio bibliográfico (IV. Clasificación temática, 8)», AM-E 27, 2009, 253-294.

Menor, M.: «Llevar lechuzas a Atenas no vale un óbolo», Paremia 18, 2009, 217-224.

Molinos TejadA, M.T.: «Violencia infantil», Teatro y sociedad en la antigüedad clásica 227-242

Moreschin, C. - Norelli, E.: Patrología. Manual de literatura cristiana antigua griega y latina. Traducción de J.M. Hernández Blanco. Salamanca, Sígueme, 2009.

NAVARRO, J.L.:enNeחE Morza Canta Musa. Madrid, Ediciones Clásicas, 2009.

PAGÁn CÁNOVAS, C.: La emisión erótica en la poesía griega. Una familia de redes de integración conceptual desde la antigüedad hasta el siglo XX. Tesis doctoral en CD-ROM. Murcia, Universidad, 2009.

PANosa Domingo, M.I.: Grècia i Egipte en l'origen del drama. El context sagrat. Tarragona, Institut Català d'Arqueologia Clàssica, 2009.

Pedro Marinero, J.C. DE: «Las tragedias griegas como fenómeno estético», Eikasia 22, 2009, 9-25.

PEREA YéBENES, S.: «Los therapeutai judíos de Egipto, una singular «república religiosa» platónica (en el De vita contemplativa de Filón de Alejandría), y la tradición literaria griega pre y post filoniana», Fuentes clásicas en el judaísmo 51-86.

PÉREZ BENITO, E.: «Mujeres, bárbaros y homosexuales: Notas al margen sobre la novela griega», en S. Moreno Tello - J.J. Rodríguez Moreno (coords.), Marginados, disidentes y olvidados en la historia, Cádiz, Universidad, 2009, 27-36.

Pérez Galicia, G.: «Los Oráculos de Histaspes. Puesta al día y análisis en el marco de la literatura apocalíptica», Minerva 22, 2009, 127-152.

Pòrtulas AmBros, J.: «El diàleg, entre la tragèdia i la filosofia», AF-SGL 25/26, 2003/2004, 289-297.

Prieto Domínguez, Á.: «Historia del centón griego», CFCG 19, 2009, 217-232.

PRIETo DomíngueZ, Á.: «¿Qué era un centón para los griegos? Preceptiva y realidad de una forma literaria no tan periférica», Myrtia 23, 2008, 135-156.

RuIZ SÁNCHEZ, M.: «La mano cortada: cuentos de ladrones de Heródoto a nuestros días (I)», Myrtia 24, 2009, 239-272.

SÁNCHEZ-Ostiz, A.: «Victorum vestigia: el influjo de las letras latinas en la cultura literaria de Grecia», EClás.136, 2009, 85-107.

Signes CODOÑER, J.: «La escritura en la Grecia arcaica: un debate metodológico», Cultura escrita y sociedad 8, 2009, 14-64.

SPATAFORA, G.: «Il fuoco d'amore. Storia di un topos dalla poesia greca arcaica al romanzo bizantino I: l'immagine del fuoco nella poesia di età arcaica e classica», Myrtia 22, 2007, 19-33.

Teja CAsuso, R.: «El agua en la literatura grecolatina», en E. Illarregui (ed.), Arqueología del agua. Herrera de Pisuerga, Ayuntamiento, 2009, 63-68.

ToRRES AsENSIO, G.: «El rapto de la esposa en las literaturas indoeuropeas», AF-SGL 25/26, 2003/2004, 335-366. 
VALCÁRCEL MARTÍNEZ, V.: «La ambigua relación entre la biografía y la historia», Las biografías griega y latina $19-40$.

VillarRuBia Medina, A.: «La mitografía griega y sus autores», Cuatro estudios 121-152.

\section{LINGÜÍSTICA GRIEGA. MÉTRICA}

Alonso DÉnIZ, A.: «Difusión de la aspiración de la /s/ intervocálica en el Peloponeso en el I milenio a. C.», $C F C G$ 19, 2009, 9-27.

Alonso DénIZ, A. - NieTo IzQuiERDo, E.: «Dialecto local y dialecto épico en las inscripciones métricas de la Argólide», Minerva 22, 2009, 83-105.

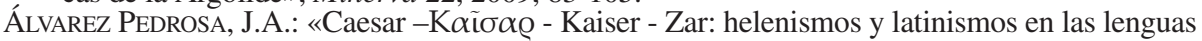
actuales», De Homero a Virgilio 111-130.

Bergua, J.: «¿Cuánto griego hablamos? Helenismos del español», De Homero a Virgilio 131-142.

ESTEVE FALQUET, M.: Kotvaí griegas: estudio dialectológico, gramatical y sociolingüístico. Tesis doctoral. Valencia, Universidad, 2009.

García RAmón, J.L.: «Lexicographia Graeca: algunos nuevos lemmata a la luz de las glosas y la onomástica», Myrtia 22, 2007, 5-18.

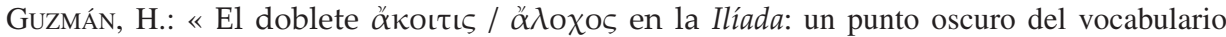
homérico», Myrtia 24, 2009, 15-27.

GuZmán Arias, C. - PÉREZ Molina, M.E.: «Tigres: rapidez, fiereza e instinto maternal», Myrtia 23, 2008, 245-258.

Lillo AlCARAz, A.: «La locución ẃs ötı en griego antiguo», Myrtia 23, 2008, 17-28.

LÓPEZ FÉREZ, J.A.: «Anotaciones sobre el término `Europa en los historiadores y geógrafos de los siglos I y II d. C.», Myrtia 24, 2009, 75-115.

LuJÁN, E.: «Jerónimo o `el sagrado nombre : etimologías de los nombres propios españoles», De Homero a Virgilio 143-164.

MARTíneZ VÁzQuEZ, R.: «Aspectos cognitivos del aspecto verbal: metonimia y presente por perfecto en griego antiguo», Habis 40, 2009, 7-16.

Méndez DosunA, J.: «Maravillas de la lengua griega», De Homero a Virgilio 55-82.

MÉNDEZ DosunA, J.: «Movimiento ficticio en griego antiguo: tras las huellas del viajero (in)visible», RESEL 29, 2009, 5-32.

Molina VAlero, C.: «Sintaxis comparada de las inscripciones bilingües greco-licias», Interlingüística 18, 2009, 779-788.

MúRCIA SÁNCHEZ, C.: «L'origen del llatí buricus «cavall petit» i el grec ßoıkóv `ase », AF-SGL 25/26, 2003/2004, 271-288.

NIETO IzQUIERDO, E.: «Notas sobre onomástica argiva: A@óïvos (SEG XI, 239)», Myrtia 24, 2009, 9-14.

Olalla SÁnchez, M.: Alfabetos del mundo (arco mediterráneo). Edición trilingüe español-inglésfrancés. Cuenca, Aldebarán, 2009.

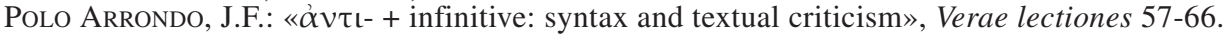

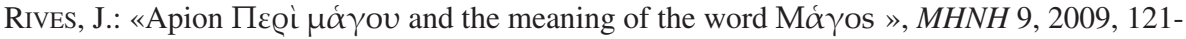

134.

SOLís BERNI, R.: «Problemas que se plantean a la hora de elaborar una tipología válida para el `número colectivo en indoeuropeo», Interlingüística 18, 2009, 1069-1078.

SowA, W.: «Griego $\zeta \alpha$ - por $\delta\llcorner\alpha$ - y algunas glosas «lesbias»», Emerita 77, 2009, $271-294$.

Striano Corrochano, A.: Formas nominales del verbo. 1 archivo de Internet. Liceus, Servicios de Gestión y Comunicación, 2009.

Striano Corrochano, A.: «De Micenas al Indo: una historia de la lengua griega en la Antigüedad», De Homero a Virgilio 15-36.

UriBe UlloA, P.: «Syneídesis en la Biblia Griega y mada' en la Biblia Hebrea. Implicaciones para una valoración del término `conciencia al interior del Antiguo Testamento, Moralia 32-121, 2009, 7-17. 
Vela TeJadA, J.: «Koiné y aticismo en Galeno, «De antidotis»: datos para un estudio lingüístico», CFCG 19, 2009, 41-61.

VILLA Polo, J. DE LA: «Syntax and textual criticism: aspect in Aeschylus’ Persae», Verae lectiones 1932.

Vives Cuesta, A.: «La palatalización de las labiovelares revisada. Antiguos problemas de reconstrucción a la luz de la tipología», Minerva 22, 2009, 65-81.

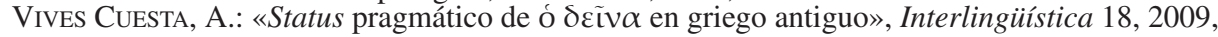
1154-1164.

\section{Micenología}

VARIas García, C.: «Fiestas religiosas griegas de tradición micénica», Perfiles de Grecia y Roma 649-656.

\section{Epigrafía. PaPirología. Numismática}

Aguilar, R.M.: «Las inscripciones de Commagene», Estudios de epigrafía griega 297-304.

ALBARRÁn MARTíNEZ, M.J.: El ascetismo femenino en Egipto según la documentación papirológica. Tesis doctoral. Universidad de Alcalá de Henares, 2009.

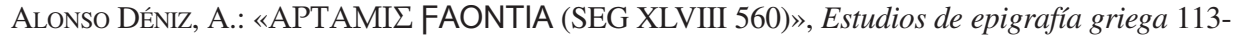
118.

Alonso Déniz, A. - Nieto IzQuierdo, E.: «Dialecto local y dialecto épico en las inscripciones métricas de la Argólide», Minerva 22, 2009, 83-105.

Amela Valverde, L.: «Mileto, Esquines y Pompeyo Magno», Helmantica 181, 2009, 7-14.

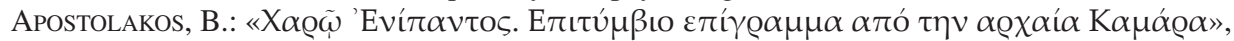
Estudios de epigrafía griega 457-468.

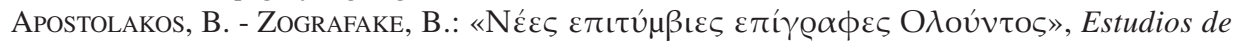
epigrafía griega 509-523.

Avram, A.: «Épigraphie et histoire religieuse: le culte de Léto dans les cités de la Mer Noire», Estudios de epigrafía griega 305-314.

BALDWIN BowsKY, M.W.: «An extra-mural sanctuary of roman Aptera?», Estudios de epigrafía griega 315-322.

BARATTA, G.: «La bella e lo specchio: algune iscrizioni greche su specchietti in piombo», Estudios de epigrafía griega 427-454.

Barrio Vega, M.L. Del: «Sobre algunas grafías del alfabeto corintio», Estudios de epigrafía griega 95-100.

Barrio Vega, M.L. Del: «Sobre la transmisión de algunos epigramas griegos», SPhV 11, 2008, 137-151.

Bermejo Rubio, F.: «Eủxì $\tau \tilde{\omega} v \pi \varrho o \beta o \lambda \tilde{\omega} v$ (P. Kell. Gr. 98): un texto maniqueo del s. IV», Helmantica 181, 2009, 73-102.

BERNABÉ, A.: «Sobre la «nueva» laminilla órfica de Feras», Estudios de epigrafía griega 323332.

BILE, M.: Epigraphie, dialectologie et lexique», Estudios de epigrafía griega 119-128.

CALderón Dorda, E.: «Tipología del hexámetro en las inscripciones funerarias griegas de los siglo II-III d.C.», Estudios de epigrafía griega 195-204.

Calero Secall, I.: «Las rentas de una propiedad: Epikarpía frente a Karpós en el código de Gortina», Estudios de epigrafía griega 129-136. 
Calvo Martínez, J.L.: «Un himno hermético en tres versiones», MHNH 9, 2009, 235-250.

CARANDE Herrero, R.: «Espondaicos epigráficos», SPhV 11, 2008, 1-25.

Carruesco García, J. - González Senmartí, A. - Rodà De llanza, I. - Tudela Penya, M.: «Una nueva propuesta educativa: máster en papirología (Tarragona, ICAC-URV)», Perfiles de Grecia y Roma 373-378.

ChAnIotis, A.: «Lament for a young man: A new epigram from Aphrodisias», Estudios de epigrafía griega 469-478.

CRESPO, E.: «La difusión temprana del dialecto ático en el Peloponeso», Estudios de epigrafía griega 137-144.

Corell, J. - Gómez Font, X.: «Las inscripciones griegas del País Valenciano (IGPV)», Estudios de epigrafía griega 25-56.

García Molinos, A. - Pérez Bentto, E.: «Voces del más allá: la necromancia en los Papiros Mágicos y en la novela griega», Perfiles de Grecia y Roma 613-620.

García TeIJeIro, M.: «Sobre las piedras-talismán del instrumental mágico de Pérgamo», Estudios de epigrafía griega 389-396.

GARCÍA VALDÉS, M.: «Notas a una inscripción como intertexto en Claudio Eliano», Estudios de epigrafía griega 221-226.

GiNestí Rosell, A.: «Las inscripciones funerarias como fuente de información sobre el estatus socio-jurídico de las mujeres extranjeras en Atenas», Perfiles de Grecia y Roma 763-772.

GonZÁlez GonZÁlez, M.: «El lamento de las madres en los epitafios griegos: una mirada a la Antología Palatina», Madres y maternidades 113-127.

GrAF, F.: «Zeus and his Parhedroi in Halikarnassos. A study on religion and inscriptions», Estudios de epigrafía griega 333-348.

Hispania Epigraphica 15 (2006). Madrid, Universidad Complutense, 2009.

Hoz GARCíA-BELLIDO, M.P. DE: «El uso de la escritura expuesta como expresión de poder y prestigio en la Grecia clásica y helenística», Cultura escrita y sociedad 8, 2009, 65-105.

Hoz García-BELLIDO, M.P. DE: «The aretalogical character of the Maionian `confession' inscriptions», Estudios de epigrafía griega 357-367.

Hoz García Bellido, M.P. DE: «Carmina Epigraphica Graeca Hispaniae», SPhV 11, 2008, 103135.

INDELLI, G.: «Le opere morali di Filodemo conservate nei Papiri Ercolanesi: un bilancio degli studi più recenti», Perfiles de Grecia y Roma 259-546.

KEESLING, C.M.: «Name forms on athenian dedications of the fifth and fourth centuries B.C.», Estudios de epigrafía griega 349-356.

LiLlo, A.: «Sobre la primera epifanía de la llamada Crónica de Lindos», Estudios de epigrafía griega $145-154$.

Magnelli, A.: «Kleobis e Biton a Delfi: realtà o leggenda?», Estudios de epigrafía griega 81-92.

MARTín GonZÁLEZ, E.: «Los epitafios griegos arcaicos en prosa», Estudios de epigrafía griega 413-424.

Martín Hernández, R.: «La catalogación de etiquetas de momia», Perfiles de Grecia y Roma 249-256.

MarTínez FernÁNDEZ, Á.: «Decretos de Aptera sobre la Asylia de Teos», Fortunatae 20, 2009, 71-80.

MARTínez FernÁNDEZ, Á.: «Epigramas de Cidonia: edición y estudio», SPhV 11, 2008, 265-282.

MARTínEZ FERnÁNDEZ, Á.: «Una nueva inscripción de un monumento funerario de Aptera», Estudios de epigrafía griega 479-486.

Martínez FernándeZ, A.: «Glandes con inscripciones encontrados en Creta», Perfiles de Grecia y Roma 257-266.

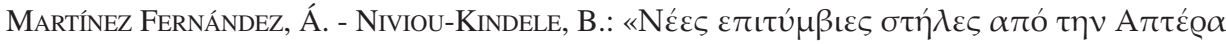

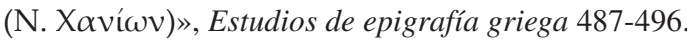


MAYER I Olivé, M.: Los honores recibidos por la familia de Marco Aurelio en la parte oriental del imperio romano: ¿Cambio o continuidad en el culto dinástico?», Estudios de epigrafía griega 277-294.

MÉNDEZ DosunA, J.: «¿Un nuevo testimonio de $\alpha i \tilde{\zeta} \alpha$ 'cabra' en una lámina órfica?», Estudios de epigrafía griega 368-376.

MigeotTe, L.: «L'apport des inscriptions à l'étude des finances publiques et sacrées des cités grecques», Estudios de epigrafía griega 251-260.

Montes Cala, J.G.: «Poesía 'epigráfica' en las Dionisíacas de Nono de Panópolis», Estudios de epigrafía griega 227-238.

NiETo IzQuierdo, E.: «A propósito de una inscripción encontrada en el Hereo de Argos IG IV, 507», Estudios de epigrafía griega 101-104.

PEREA YÉBENES, S.: «El demon mágico Phrên y el escarabajo solar egipcio», MHNH 9, 2009, 79-120.

PetZL, G.: «Bedrohter Kultvollzug: Hilfe von höherer Stelle», Estudios de epigrafía griega 377-386.

RAMíREz SÁDABA, J.L.: «La epigrafía griega hallada en la Península Ibérica», Estudios de epigrafía griega $57-77$.

RAMíREZ SÁNCHEZ, M.: «Epigrafía y cultura escrita en la antigüedad clásica», Cultura escrita y sociedad 8, 2009, 7-13.

RodríGUEZ Somolinos, J.: «Notas lexicográficas. Addenda epigraphica a DGE VII», Estudios de epigrafía griega $155-166$.

SÁnchez Ortiz De LandalucE, M.: «Elementos míticos en el epigrama inscripcional», Estudios de epigrafía griega 205-218.

SANTIAGo Álvarez, R.A.: «Epigrafía y léxico jurídico: algunos ejemplos», Estudios de epigrafía griega $167-178$.

Torallas Tovar, S.: «Papirología en España hoy», Perfiles de Grecia y Roma 155-166.

TORRES, J.B.: «El himno de Epidauro a la Madre de los dioses: epigrafía e intertextualidad», Estudios de epigrafía griega 239-248.

TRACY, S.V.: «Dating by lettering in greek epigraphy: general styles and individual hands», Estudios de epigrafía griega 105-112.

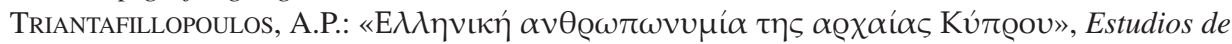
epigrafía griega 181-194.

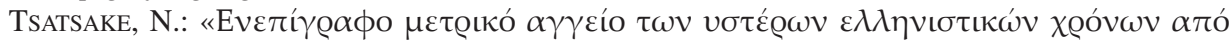

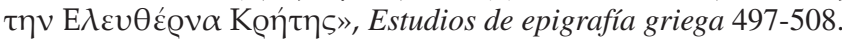

TZIFOPOULOS, Y.Z.: «Two unpublished inscriptions from the Rethymno prefecture», Estudios de epigrafía griega $525-532$.

Velasco LÓPEZ, M.H.: «Los inicios de la epigrafía según los mitos griegos», Estudios de epigrafía griega 399-410.

\section{HistORIA DE LOS TEXTOS}

Ángel Espinós, J.: «El códice Complutensis Graecus 22: su destrucción y posterior recuperación», Perfiles de Grecia y Roma 177-184.

Bernabé Pajares, A.: «Problemas de edición de textos fragmentarios: el caso de los órficos», Verae lectiones 267-290.

Besso, G. - Guagliumi, B. - Pezzoli, F.: «Un' edizione italiana commentata della Politica di Aristotele: problemi de traduzione e di critica testuale», Verae lectiones 95-126.

CALDERÓn DordA, E.: «La tradición indirecta en la crítica textual griega. El texto de Eurípides en Plutarco», Verae lectiones 33-56.

García VALDÉs, M.: «Editar a Eliano: problemas que plantea», Verae lectiones 227-266. 
GonZÁlez SuÁreZ, M.: «El copista: ¿artesano o creador?», Habis 40, 2009, 277-288.

HERNÁNDEZ MuÑZ, F.: «Recentiores non semper deteriores. Nuevos materiales para una vieja discusión», Verae lectiones 355-376.

LEganés MoYa, P.: «La transmisión del discurso Sobre la embajada fraudulenta de Demóstenes en los manuscritos españoles», Verae lectiones 127-142.

LUCK, G.: «Conjectural emendation in the greek New Testament», Verae lectiones 169-202.

MontanARI, F.: «Ekdosis alessandrina: il libro e il texto», Verae lectiones 143-168.

PÉREZ MARTín, I.: «Novedades en catalogación de manuscritos griegos. Una visión crítica», Emerita 77, 2009, 336-344.

Polo ArRondo, J.F.: «ảv $\tau_{1-}+$ infinitive: syntax and textual criticism», Verae lectiones 57-66.

PRIETO Domínguez, O.: «Epistulae et amphilochia patriarchae Photii: mezcla confusión de elementos en la constitutio textus de ambos corpora», Verae lectiones 291-320.

Ruiz YamuZA, E.: «El Fedro de Platón en manuscritos españoles. IV: el Matritensis 4569», Habis 40, 2009, 69-80.

SANZ Morales, M.: «Testimonio de los papiros y tradición medieval: (una versión diferente de la novela de Caritón?», Verae lectiones 203-226.

Urbán Fernández, A.: «Bezae codex cantabrigiensis (D): intercambios vocálicos en el texto griego de Juan», CCO 6, 2009, 375-403.

VALENTE, S.: «Il ruolo di Timeo Sofista nella constitutio textus della Repubblica di Platone», Verae lectiones 67-94.

Villa Polo, J. De La: «Syntax and textual criticism: aspect in Aeschylus' Persae», Verae lectiones $19-32$

\section{Historia. Cultura. Sociedad}

AA.VV.: Batallas de Grecia y Roma. Colección. Grecia. 19 vols. Barcelona, RBA, 2009.

AA.VV.: Reflejos de Apolo. Deporte y arqueología en el Mediterráneo antiguo = Reflections of Apollo. Sport and archaeology in the ancient Mediterranean (Museo de Zaragoza, Octubre 2009 - Enero 2010. Zaragoza, Departamento de Educación, Cultura y Deporte del Gobierno de Aragón, 2009.

Andreu Pintado, J. (ED.): Los vascones de las fuentes antiguas: en torno a una etnia de la antigüedad peninsular. Barcelona, Universidad, 2009.

Antela Bernárdez, B.: Pèricles no hi é. Breu història de l'antiga Grècia. Barcelona, UOC, 2009.

Bengtson, H.: Historia de Grecia. Introducción de C. Schrader. Traducción de J. Calonge. Barcelona, RBA, 2009.

CARTLEdge, P.: Los espartanos. Una historia épica. Barcelona, Ariel, 2009.

CAssin Scott, J. - Sekunda, N. - Fields, N.: Guerreros de la Liga Helénica. Ilustraciones de Peter Bull, J. Cassin Scott y A. McBride. Traducción de I. Galera Ibáñez. Barcelona, RBA, 2009.

ChIC GARCíA, G.: El comercio y el Mediterráneo en la antigüedad. Madrid, Akal, 2009.

Ciccotтi, E.: El ocaso de la esclavitud en el mundo antiguo. Traducción de M. Domenge Mir. Valladolid, Maxtor, 2009.

FERNÁNDEZ GARCÍA, V.: «Los trabajos femeninos en el Oikos de la Grecia Clásica: la madre, la cuidadora, la administradora», Cuestiones de género. De la igualdad y la diferencia 4, 2009, 15-50.

GARCía SÁnCHEZ, M.: El gran rey de Persia: formas de representación de la alteridad persa en el imaginario griego. Barcelona, Universidad, 2009.

GonzÁlez Blanco, A.: «La Antigüedad tardía. Renovación y perspectivas», Perfiles de Grecia y Roma 669-710. 
GonZÁlez Soutelo, S.: «Los baños de agua del mar en el mundo antiguo: una propuesta de estudio», Gallaecia 27, 2008, 227-240.

JiMÉNEZ JiMÉNEZ, A.F.: Manual didáctico de historia y mitología griega. Almería, Corintia, 2009.

KagAn, D.: La guerra del Peloponeso. Barcelona, Edhasa, 2009.

LACARRIÈre, J.: Verano griego. 4000 años de Grecia cotidiana. Traducción de D. Fernández Jiménez. Badalona - Madrid, Altaïr - Asociación Cultural Hispano-Helénica, 2009.

LONGO, O.: El universo de los griegos. Actualidad y distancias. Barcelona, El Acantilado, 2009.

Marco Simón, F. - Pina Polo, F. - Remesal Rodríguez, J.(EDS.): Formae mortis. El tránsito de la vida a la muerte en las sociedades antiguas. Actas del Coloquio Internacional de Historia Antigua. Barcelona, Universitat de Barcelona, 2009.

Mercer, Ch.E.: Breve historia de Alejandro Magno. Traducción de S. Suárez Sánchez de León. Nueva edición revisada y ampliada. Madrid, Nowtilus, 2009.

Montanelli, I.: Historia de los griegos. Traducción de D. Pruna. Barcelona, Backlist, 2009.

Montanelli, I.: Història dels grecs. Traducció de J. Casas. Barcelona, Destino, 2009.

Morère Molinero, N. (ED.): Viajes en el Mediterráneo antiguo. Madrid, Editorial Centro de Estudios Ramón Areces - Universidad de Sevilla, 2009.

Negrete, J.: La gran aventura de los griegos. Madrid, La Esfera de los Libros, 2009.

Plaza Pazos, B.: Cómo entender mejor el imperialismo ateniense. 1 CD-ROM. Málaga, Ediped, 2009.

PociÑa PÉREZ, A. - García GonZÁLEZ, J.M. (EDS.): En Grecia y Roma III. Mujeres reales y ficticias. Granada, Universidad, 2009.

QUESADA SANZ, F.: Ultima ratio regis. Control y prohibición de las armas desde la antigüedad a la edad moderna. Madrid. Polifemo, 2009.

Rodríguez Vargas, M.: La Grecia 'vieja'. Almería, Tutorial Formación, 2009.

SAlVAdOR, J.L.: El deporte en Occidente. Grecia, Roma, Bizancio. Madrid, Cátedra, 2009.

SANCHO RocheR, L.: ¿Una democracia perfecta? Consenso, justicia y demokratia en el discurso político de Atenas (411-322 a.C.) Zaragoza, Institución Fernando el Católico, 2009.

Sanz Mínguez, C. - Romero CARnicero, F. (EDS.): El vino y el banquete en la Europa prerromana. Valladolid, Universidad - Centro de Estudios Vacceos Federico Wattenberg, 2009.

SCHNEIDER, H.: La técnica en el mundo antiguo. Una introducción. Traducción de J. Martínez. Madrid, Alianza, 2009.

SORIA GómEZ, M.Á.: Análisis de textos clásicos sobre la fundación de ciudades en la Antigüedad. 1 CD-ROM. Don Benito, Edita, 2009.

Vera Aranda, Á.L.: Breve historia de las ciudades del mundo antiguo. Madrid, Nowtilus, 2009.

VEYNE, P.: El imperio grecorromano. Madrid, Akal, 2009.

WATERFIELD, R.: La retirada de Jenofonte. Grecia, Persia y el final de la Edad de Oro. Traducción de J.L. Gil Aristu. Madrid, Gredos, 2009.

WeBER, M.: Fundamentos sociales de la decadencia de la cultura antigua. Introducción de L. M. Valdés Villanueva. Traducción de S. Recio Muñiz. Oviedo, KRK, 2009.

\section{Religión. Mitología}

Alba Ugalde, C.M. Et AliI: El camino de los mitos II. Madrid, Evohé, 2009.

Arroyo De La Fuente, M.A.: Iconografía de Hermes en el arte clásico. 1 archivo de Internet.

Madrid, Liceus, Servicios de Gestión y Comunicación, 2009.

ASENSI, J.: Layos: la historia de un mito griego. Madrid, Evohé, 2009.

BERNABÉ, A.: «Democracia y religión griegas», Filosofía y democracia en la Grecia antigua 89-102.

BURKERT, W.: La creación de lo sagrado. La huella de la biología en las religiones antiguas.

Traducción de S. Mastrangelo. Barcelona, El Acantilado, 2009. 
CABRERA, P.: «Nereidas, tritones, delfines. Imágenes y mitos marinos en la Grecia clásica», Perfiles de Grecia y Roma 855-880.

Calvo Martínez, J.L.: «Un himno hermético en tres versiones», MHNH 9, 2009, 235-250.

CANTARella, E.: El dios del amor. Una introducción a los mitos y leyendas de la Antigüedad. Traducción De J.M. Furió Sancho. Barcelona, Paidós , 2009.

CASAdIO, G.: «Mythos vs. Mito», Minerva 22, 2009, 41-63.

ECharte Cossío, M.J.: «Coloquio de los Centauros: arquitectura de los mitos», Anales de literatura hispanoamericana 38, 2009, 157-182.

ELVIRA SÁNCHEZ, I.: «Hermetismo, neoplatonismo y teurgia», MHNH 9, 2009, 5-29.

FERRY, L.: La sabiduría de los mitos. Aprender a vivir 2. Traducción de I. Cifuentes. Madrid, Taurus, 2009.

FowleR, R.L.: «Thoughts on Myth and Religion in Early Greek Historiography», Minerva 22, 2009, 21-39.

FoX, R.L.: Héroes viajeros. Los griegos y sus mitos. Barcelona, Crítica, 2009.

García Alcina, B.: Mitos griegos. Castellón, Discóbolo, 2009.

García Gual, C.: Encuentros heroicos. Seis escenas griegas. Madrid, Fondo de Cultura Económica de España, 2009.

García Gual, C.: Prometeo. Mito y literatura. Madrid, Fondo de Cultura Económica de España, 2009.

García Molinos, A. - Pérez Benito, E.: «Voces del más allá: la necromancia en los Papiros Mágicos y en la novela griega», Perfiles de Grecia y Roma 613-620.

Gentil García, I.: «La mitología griega y los pies: Pan el dios sin pies», Revista española de podología 20/4, 2009, 146-150.

Guarino OrtegA, R.: «El poeta Adonis, puente entre Oriente y Occidente», Myrtia 23, 2008, 417426.

Hidalgo De La Vega, M.J.: «Misticismo y misterios. Reflexiones a propósito de la edición inglesa de un libro reciente», Studia Historica. Historia Antigua 27, 2009, 207-227.

JiMÉNEZ JIMÉNEZ, A.F.: Breve historia de la religión griega. Almería, Corintia, 2009.

JiMÉnEZ JiMÉnEZ, A.F.: Manual didáctico de historia y mitología griega. Almería, Corintia, 2009.

JimÉNEZ SAn CRISTóBAl, A.I.: «Dionisio Melanégida», Perfiles de Grecia y Roma 621-630.

KERÉNYI, K.: Imágenes primigenias de la religión griega 1. El médico divino. Traducción de B. Kiemann. Madrid, Sexto Piso, 2009.

KerÉNYI, K.: Los héroes griegos. Prólogo J. Portulas. Traducción de C. Serna 2009.

Martínez Nieto, R.B.: «La política dinástica de Corinto en la tradición mítica de época arcaica», Perfiles de Grecia y Roma 791-798.

MÉNDEZ FILESI, M.: El laberinto. Historia y mito. Barcelona, Alba, 2009.

Menor, M.: «Llevar lechuzas a Atenas no vale un óbolo», Paremia 18, 2009, 217-224.

Mitógrafos griegos: Palefato, Heráclito, Anónimo Vaticano, Eratóstenes, Cornuto. Introducción, traducción y notas de J.B. Torres Guerra. Madrid, Gredos, 2009.

PADEL, R.: A quien los dioses destruyen. Elementos de la locura griega y clásica. Traducción de G. Rosemberg. Madrid, Sexto Piso, 2009.

PARRAMÓn I Blasco, J.: Diccionari de la mitologia grega i romana. Barcelona, Edicions 62, 2009.

Perea YéBENES, S.: «El demon mágico Phrên y el escarabajo solar egipcio», MHNH 9, 2009, 79-120.

Perea YéBENES, S.: «Prescripciones rituales sobre la impureza sexual de la mujer: coincidencias funcionales entre algunas Leyes Sagradas griegas y Septuaginta Lv 12 y 15, 18-33 (2 $2^{\mathrm{a}}$ parte)», CCO 6, 2009, 253-285.

Pérez Galicia, G.: «Los Oráculos de Histaspes. Puesta al día y análisis en el marco de la literatura apocalíptica», Minerva 22, 2009, 127-152. 
Plácido SuÁRez, D.: «Las islas Casitérides. En los límites de la realidad», Studia Historica. Historia Antigua 27, 2009, 49-56.

RAPHALS, L.: «En la intersección entre poder y predicción: aspectos sobre la adivinación en China y Grecia antiguas», en A. Relinque Eleta (coord.), La construcción del poder en la China antigua, Granada, Universidad, 2009.

Reboreda Morillo, S.: «Penélope: la maternidad en el caos», Madres y maternidades 47-66.

RitoRÉ PONCE, J.: «Heracles en la encrucijada: significados y metamorfosis del mito en la literatura griega antigua», Cuatro estudios 61-120.

RodRíGUEZ LóPEZ, M.I.: Iconografía de Posidón en el arte griego. 1 archivo de Internet. Madrid, Liceus, Servicios de Gestión y Comunicación, 2009.

RodríGuez LóPeZ, M.I.: Las armas de Aquiles. 1 archivo de Internet. Madrid, Liceus, Servicios de Gestión y Comunicación, 2009.

Rodríguez Peinado, L.: Dionisio y lo dionisíaco en los tejidos del Valle del Nilo. 1 archivo de Internet. Madrid, Liceus, Servicios de Gestión y Comunicación, 2009.

RodríGUez PÉREZ, D.: Serpientes, dioses y héroes. El combate contra el monstruo en el arte y la literatura griega antigua. León, Universidad, 2009.

SAnZ Mingo, C.A.: «Forcing the Bull into its knees: the Mithraic Strife in Modern Arthuriana», Minerva 22, 2009, 205-215.

Schwab, G.: Las más bellas leyendas de la Antigüedad clásica. Prólogo de V. Cristóbal. Traducción de F. Payarols. Madrid, Gredos, 2009.

Solís Miranda, J.A.: Pandora. El mito. La Coruña, Cadena Cien Editores, 2009.

Tiemblo Magro, A.: La muerte y el más allá en el mundo antiguo. Un recorrido sobre textos escogidos desde el 30000 al 200 a.C. Prólogo de F. Lara Peinado. Madrid, Dilema, 2009.

VALDÉs GuíA, M.: «Los Teseidas, la colonización de Sigeo y el Quersoneso tracio en el imaginario ateniense arcaico», Studia Historica. Historia Antigua 27, 2009, 57-72.

VARIAS GarCíA, C.: «Fiestas religiosas griegas de tradición micénica», Perfiles de Grecia y Roma 649-656.

Velasco LóPez, M.H.: «Adonis y el jabalí», Perfiles de Grecia y Roma 657-664.

VILARIÑo RodrígUEZ, J.J.: Heracles o la temible distancia del héroe griego. Tesis doctoral. Vitoria, Universidad del País Vasco, 2009.

VILARIÑo RodríGUeZ, J.J.: «Heracles y los pueblos arqueros de la antigüedad», Studia Historica. Historia Antigua 27, 2009, 31-48.

Villarrubia Medina, A.: «La mitografía griega y sus autores», Cuatro estudios 121-152.

\section{CRISTIANISMO PRIMITIVO}

AlbarRán MARTínez, M.J.: El ascetismo femenino en Egipto según la documentación papirológica. Tesis doctoral. Universidad de Alcalá de Henares, 2009.

Álvarez CineIra, D.: Pablo y el imperio romano. Madrid, Sígueme, 2009.

BLÁZqueZ MARTíNEZ, J.M.: «La integración del cristianismo en la sociedad persa (siglos III-IV)», en G. Bravo Castañeda - R. González Salinero (coords.), Formas de integración en el mundo romano. Actas del VI Coloquio de la Asociación Interdisciplinar de Estudios Romanos, Madrid, Signifer, 2009, 149-160.

Charlesworth, J.H.: Jesús y la arqueología. Traducción de J.P. Tosaus Abadía. Estella, Verbo Divino, 2009.

ChurruCA, J. DE: Cristianismo y mundo romano. Nuevos estudios. Madrid, Marcial Pons, 2009.

DunN, J.D.G.: Jesús recordado. El cristianismo en sus comienzos 1. Traducción de S. Fernández Martínez. Estella, Verbo Divino, 2009. 
GIORDA, M.: «La direction spirituelle à travers les règles monastiques. Péchés, pénitence et punitions dans le monachisme pachômien (IVe-Ve siècles)», CCO 6, 2009, 95-113.

HARD, R.: El Gran libro de la mitología griega. Basado en el Manual de mitología griega de H.J. Rose. Traducción de J. Cano Cuenca. Madrid, La esfera de los libros, 2009.

MARCOS SÁNCHEZ, M.M.: «De la convivencia a la exclusión. Reflexiones sobre el discurso de la tolerancia religiosa en el cristianismo antiguo», Perfiles de Grecia y Roma 631-638.

MARKSCHIES, Chr.: ¿Por qué sobrevivió el cristianismo en el Mundo Antiguo? Contribución al diálogo entre la historia eclesiástica y la teología sistemática. Salamanca, Sígueme, 2009.

Moreno PAMPLIEGA, J.: «Apologética y verdad: una controversia interreligiosa en el siglo III», Perfiles de Grecia y Roma 567-574.

STARK, R.: La expansión del cristianismo. Un estudio sociológico. Madrid, Trotta, 2009.

VAAGE, L.E.: «Earliest Christian Ascetism \& the Early Christian Family», EB 67, 2009, 303-328.

\section{Filosofía. CienCia}

BERTI, E.: En el principio era la maravilla. Las grandes preguntas de la filosofía antigua. Madrid, Gredos, 2009.

BURKERT, W.: La creación de lo sagrado. La huella de la biología en las religiones antiguas. Traducción de S. Mastrangelo. Barcelona, El Acantilado, 2009.

CASADESÚS BORDOY, F.J.: «La dimensión cósmica, ética y epistemológica del concepto de `medida' en la Filosofía Griega», Perfiles de Grecia y Roma 477-498.

DORION, L.A.: Sócrates. Barcelona, Davinci, 2009.

ELVIRA SÁNCHEZ, I.: «Hermetismo, neoplatonismo y teurgia», MHNH 9, 2009, 5-29.

FERnÁNDEZ, C.: Los filósofos antiguos. Selección de textos. Madrid, Biblioteca de Autores Cristianos, 2009.

FERRACES RodríGUEZ, A. (ED.): Fito-zooterapia antigua y altomedieval: textos y doctrinas. La Coruña, Universidad, 2009.

FuENTES GONZÁLEZ, P.P.: «La amistad desde la perspectiva y la experiencia de los cínicos antiguos», $L a$ amistad en la filosofía antigua 43-62.

GARcía-BARó, M.: Sócrates y herederos. Introducción a la historia de la filosofía occidental. Salamanca, Sígueme, 2009.

García QuinTEla, M.V.: «Filosofía presocrática y formas políticas», Filosofía y democracia en la Grecia antigua 41-88.

Giatrakou, M.E.: «Socrates as teacher of virtue and his conscience for his ignorance», Perfiles de Grecia y Roma 521-528.

GRAU, S.: Antologia obituària dels filòsofs de la Grècia antiga. Barcelona, Adesiara, 2009.

HÜBNER, W.: «Wie kommen die Seelen vom Tierkreis auf die Erde?», MHNH 9, 2009, 175-190.

ILDEFONSE, F.: «Sympatheia, philia», La amistad en la filosofía antigua 135-146.

Jenkind, I. - Clare TuRner, V.: La belleza del cuerpo. Arte y pensamiento en la Grecia Antigua (Abril - Septiembre 2009, MARQ). Alicante, MARQ, 2009.

KomorowsKa, J.: «Astrology, Ptolemy and technai stochastikai», MHNH 9, 2009, 129-140.

LAKS, A.: El vacío y el odio. Elementos para una historia arcaica de la negatividad. Traducción de L. Irribarren. Madrid, Arena Libros, 2009.

LEAO, D.F.: «Do polites ao kosmopolites», AEF 32, 2009, 157-174.

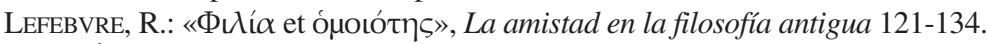

LLEDÓ Í̃̃IGO, E.: «Amistad y memoria», La amistad en la filosofía antigua 19-30.

Macías Villalobos, C.: «Algunas notas sobre el ideario y el modo de vida cínicos», AM-E 26, 2009, 13-40. 
Martín García, F. - Talavera Cuesta, S.: De Tales a Parmenisco. Cuenca, Universidad de Castilla-La Mancha, 2009.

MARTínez García, J.A.: «Virtud (areté) y vocación a ser persona en la tradición clásica griega», $F a$ cies Domini. Revista alicantina de estudios teológicos 1, 2009, 217-232.

Martínez SaURA, F.: Diccionario de mineralogía en el mundo clásico. Castellón, El Lago, 2009.

Menage, G.: Historia de las mujeres filósofas. Introducción y notas de R. Rius Gatell. Barcelona, Herder, 2009.

MASCI, M.O.: «Michel Foucault y la relación pastor-rebaño en las culturas griega y latina», Isegoría. Revista de filosofía moral y política 40, 2009, 221-233.

Ortega Monasterio, M.T. - Barco Del Barco, F.J. Del.: «La ciencia griega en los manuscritos hebreos de la Comunidad de Madrid», Fuentes clásicas en el judaísmo 165-188.

Perea YéBEnES, S.: «Algunas consideraciones sobre la iatraléptica antigua y la constitución de Vespasiano a favor de los médicos de Pérgamo», FI 20, 2009, 201-225.

Pérez JiméneZ, A.: Paradigmas de nuestra cultura. Astrología y poder político en la Antigüedad. Discurso pronunciado en el acto de ingreso en la Sociedad Erasmiana de Málaga por el Dr. D. Aurelio Pérez Jiménez, y contestación del Dr. D. Cristóbal Macías Villalobos (Málaga, 24 de abril de 2009). Málaga, Grupo Editorial 33, 2009.

PlácIDo SuÁREZ, D.: «Sofística, retórica y democracia», Filosofía y democracia en la Grecia antigua $127-160$.

Ramos JuRAdo. E.A.: «Del antialegorismo de Platón al alegorismo de su entorno. Poesía y filosofía en Grecia en el siglo IV a.C.», Cuatro estudios 9-60.

Redondo ReYes, P. - LóPEz RodríGuez, C.: «Astronomía griega y armonía de las esferas», Perfiles de Grecia y Roma 591-600.

Sambursky, S.: El mundo físico a finales de la Antigüedad. Traducción de C. Solís. Madrid, Alianza Editorial, 2009.

SÁnchez Moreno, G.: Escritos encontrados de filosofía antigua. Madrid, Manuscritos, 2009.

SANCHO RocheR, L.: «Entre tradición y revolución: La `fundación' de la demokratía», Filosofía y democracia en la Grecia antigua 15-40.

Segura Munguía, S. - Torres RiPA, J.: Historia de las plantas en el mundo antiguo. Madrid - Bilbao, CSIC - Universidad de Deusto, 2009.

Solana Dueso, J.: «Philía: entre eros y dike», La amistad en la filosofía antigua 31-42.

SoFISTAS. Testimonios y fragmentos. Introducción, traducción, notas e índices de F. Martín García. Madrid, Ediciones Clásicas, 2009.

Soriano PalaO, J.: La medicina pre-técnica en la antigua Grecia. Discurso de presentación por Rafael Carmena Rodríguez. Murcia, Real Academia de Medicina y Cirugía de Murcia, 2009.

\section{Pervivencia. Humanismo. Historia de la Filología}

ADRADOS, F.R.: «Esbozo de las líneas generales del influjo del mundo greco-latino en las lenguas de Europa», Perfiles de Grecia y Roma 95-102.

AhMED IsMAIL, R.: «La figura de Penélope en Ítaca de Francisca Aguirre como configuración de la soledad: psicología íntima y simbolismo mítico», Cal.Ren.8, 2007, 7-24.

ALAVEDRA I REGÁs, J.: «El teatro griego en Un hombre que se parecía a Orestes de Álvaro Cunqueiro», Garoza. Revista de la Sociedad Española de Estudios Literarios de Cultura Popular 9, 2009.

Alba Ugalde, C.M: El camino de los mitos II. Madrid, Evohé, 2009.

Alcalde, C. - Asencio, P. - Macías, C.: «Picasso y la mitología clásica», Myrtia 22, 2007, 297-317.

AlganZa RoldáN, M.: «Narciso de Max Aub: tradición y actualidad de un tema mítico-literario», En recuerdo de Beatriz Rabaza 45-62. 
Almeida CARdoso, Z. DE: «Reflexos das Medéias clássicas no teatro brasileiro contemporâneo», En recuerdo de Beatriz Rabaza 167-180.

Alonso GuARDo, A.: «Apuntes sobre el léxico ginecológico en el De mulierum affectibus del Corpus hippocraticum», La filología latina. Mil años más 117-136.

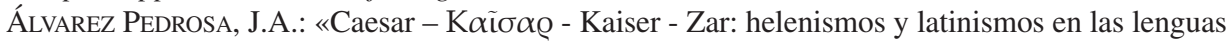
actuales», De Homero a Virgilio 111-130.

Alvarez VAladÉs, J.: «Mundo clásico, voz lírica femenina y expresión del deseo en la poesía de Aurora Luque», Minerva 22, 2009, 217-23.

Amado Blanco, T.: «Agamenón vuelve a Áulide», En recuerdo de Beatriz Rabaza 63-72.

ANGELís, D.: «El pensamiento de lo trágico a través de las críticas teatrales del escritor Emilios Jurmuzios», En recuerdo de Beatriz Rabaza 33-44.

Arcos Pereira, T. - Cuyás De Torres, M.E.: «La enseñanza de la Retórica en los Scholia in Aphthonii progymnasmata de Juan de Mal Lara», Cal.Ren.8, 2007, 25-34.

ARPes, M. - ATIEnZA, A. - ZAPATA, P.: «Medea en tierras de España. Una versión posmoderna de la tragedia clásica por el dramaturgo español Fermín Cabal», En recuerdo de Beatriz Rabaza 73 84.

Badrines Passani, F.: Presència de la filosofia aristotèlica en l'obra de C.S. Lewis. Barcelona, Universidad, 2009.

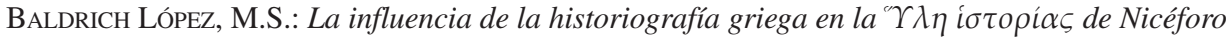
Brienio. Tesis doctoral. Granada, Universidad, 2009.

BALLó, J.: Els riscos del saber. Barcelona, Galàxia Gutenberg-Cercle de Lectors, 2009.

Bañuls Oller, J.V. - Morenilla TAlens, C.: «La nueva dramaturgia clásica: Aquel aire infinito de Lluïsa Cunillé» En recuerdo de Beatriz Rabaza 85-102.

BARnés VÁzQuez, A.: 'Yo he leído en Virgilio'. La tradición clásica en el Quijote. Prólogo por J. Canavaggio. Vigo, Academia del Hispanismo, 2009.

BARRANCO, M.I.: «Mujeres que danzan en el aire», En recuerdo de Beatriz Rabaza 103-110.

Barrios Castro, M.J.: «Un fragmento ficticio de Safo en Ezra Pound: ¿pseudocita o monólogo dramático?», CFCG 19, 2009, 233-244.

BEN MRAD, I.: «Les gloses botaniques andalouses sur le manuscrit de Paris de la traduction arabe de la Materia Medica de Dioscorides», Al-Qantara 30/2, 2009, 581-622.

Benítez Rodríguez, E.: «Proverbios, tópicos y mitología clásica: relación con el refranero castellano (II)», Paremia 18, 2009, 88-98.

Bennardo, F.G. DI: El canto de Euridice. Sevilla, Arcibel, 2009.

BerguA, J.: «¿Cuánto griego hablamos? Helenismos del español», De Homero a Virgilio 131142.

Biglieri, A.A.: «La Argentina de Antígona Vélez», En recuerdo de Beatriz Rabaza 111-122.

Blázquez, J.M.: Cristianismo y mitos clásicos en el arte moderno. Madrid, Cátedra, 2009.

Buisel De Sequeiros, M.D.: «El cántico de las sibilas en De temporum fine comoedia de Carl Orff», En recuerdo de Beatriz Rabaza 111-122.

BuzÓN, R.P. - TORRES, D.: «Representaciones del poder en el lenguaje del mito: Orestía de Esquilo y Las Moscas de J.P. Sartre», En recuerdo de Beatriz, Rabaza 137-144.

Caballero Del Sastre, E.: «El canto de Orfeo en Latinoamérica: Orfeu da Conceição de Vinicius de Moraes (1956) y La casa sin sosiego de Griselda Gambaro y Gerardo Gandini (1992)», En recuerdo de Beatriz Rabaza 145-152.

CABrero, M.C.: «Argentinidad de Medea: de la Cólquide a Moquehua, via Coliqueo», En recuerdo de Beatriz Rabaza 153-166.

CAlero SeCall, I.: «Presencia del mito clásico en la obra de Gil Vicente», Cal.Ren.8, 2007, 51-64.

CAMPANINI, S.: «Porte iusticie. L'Iggeret ha-qodes nella traduzione di Flavio Mitridate», Fuentes clásicas en el judaísmo 143-164. 
CAPElli, P.: «Tre fonti mediche greche di Nahmanide», Fuentes clásicas en el judaísmo 117-142.

Casas Agudo, A.: «Moũ $\alpha \alpha \lambda \varepsilon \pi \tau \alpha \lambda \varepsilon ́ \alpha$ / Musa levis / Blanda Musa: concisión y sutileza como presupuesto poético elegíaco desde Calímaco al Renacimiento», FI 20, 2009, 39-77.

Cerezo Magán, M.: «El subconsciente clásico en Eugeni d'Ors», EClás.136, 2009, 109130.

Cerrillo Martín De CÁceres, E.: «La antigüedad en la Extremadura de los siglos XVI y XVII: entre la invención y la representación», Nulla dies sine linea 53-72.

Chase, C.: Peregrinando por el Peloponeso. Madrid, Ediciones Clásicas, 2009.

EMBERGER, B.L.: «Hans Limbach: cuando Phädra se convierte en reina de las Amazonas», En recuerdo de Beatriz Rabaza 211-226.

FuENTES GONZÁLEZ, P.P.: «Función de la mitología clásica en dos escritores murcianos del Barroco: el humanista Cascales y el diplomático Saavedra Fajardo», Myrtia 22, 2007, 257-295.

Gaja, R. - KazZazí, M.J. - NikoubaKht, N.: «La poesia d'Omar Khayam i els tòpics literaris occidentals», AuOr. 26, 2008, 213-229.

Galán, L.: «Fedra: de Séneca a Sarah Kane», En recuerdo de Beatriz Rabaza 227-238.

GALlardo LóPEZ, M.D.: «La mitología clásica en dos maestros catalanes del siglo XX», La filología latina. Mil años más 1803-1813.

GAMBÓN, L.: «Medea mapuche o el diálogo Eurípides - Juan Radrigán», En recuerdo de Beatriz Rabaza 239-250.

García FernándeZ, A.M.: «Hegel interpreta a Sófocles», en Res Publica Litterarum 2009.

García Gual, C.: «Sobre los Ensayos de Montaigne y sus precursores», EClás.135, 2009, 77-90.

GarCía Sola, M.C.: «La `otra' Antígona de Jean Anouilh», En recuerdo de Beatriz Rabaza 251-264.

GIL FERnÁndeZ, L.: «Antecedentes medievales del Humanismo valenciano», Perfiles de Grecia y Roma 381-396.

GILABERT BARBERÀ, P.: «New York versus Tragedy and Oedipous: the legacy of Sophocles and the Sophists in Woody Allen's Crimes and misdemeanors», AF-SGL 25/26, 2003/2004, 179-193.

García JuRADO, F.: «En torno al concepto 'clásico' en el siglo XVII: los autores grecolatinos en la República literaria», Antiguos y modernos 149-160.

Gómez ARANDA, M.: «La recepción del pensamiento de Claudio Ptolomeo en el judaísmo medieval», Fuentes clásicas en el judaísmo 189-212.

GonzÁlez De MendozA, L.: De Ilión a Ítaca. Madrid, Proyectos Editoriales Cave Canem, 2009.

GonzÁlez De Tobía, A.M.: «Los reyes en su laberinto», En recuerdo de Beatriz Rabaza 265-276.

GonZÁlez Delgado, R.: «Un soneto griego de Gonzalo Correas a la muerte de Felipe III», Nulla dies sine linea 131-142.

GoNZÁLEZ LUIS, F.: «Oscilaciones de género gramatical en la latinización de los masculinos griegos de la primera declinación», La filología latina. Mil años más 79-76.

GonZÁlez-Rivas Fernández, A.: «La educación y los clásicos en The Mill on the Floss, de George Eliot», Antiguos y modernos 241-258.

GonZÁlez Vega, F.: «Trayectorias del clasicismo hispánico. La escogida senda de Menéndez Pelayo en los umbrales del siglo XXI», Antiguos y modernos 285-310.

GonZÁLEZ-RIVAS FernáNDEZ, A.: «Margaret Fuller: los clásicos al servicio de la retórica femenina», Pectora mulcet 1295-1306.

GouguenheIm, S.: Aristóteles y el Islam. Las raíces griegas de la Europa cristiana. Traducción de A. Escartín. Madrid, Gredos, 2009.

HeEsAKKers, Chr.: «Erasmo filólogo», Myrtia 23, 2008, 259-286.

Herrero Cecilia, J.: «Ariane de J.M.G. Le Clézio y la reescritura del mito del minotauro en el laberinto de una ciudad fantasmagórica», Amaltea. Revista de mitocrítica 1, 2009, 115-131.

Hualde Pascual, P.: «Fuentes griegas y latinas de Mitrídates, Rey del Ponto, de Fray Francisco del Castillo, `El ciego de la Merced'», CFCG 19, 2009, 183-216. 
KIRK, G.S.: Hacia el mar Egeo. Memorias de un helenista durante la Segunda Guerra Mundial. Madrid, Gredos, 2009.

Konstan, D.: «The miser's daughter from Menander to George Bernard Shaw», En recuerdo de Beatriz Rabaza 277-290.

LASA OTХOTEKо, C.: «Humor y comicidad: la aportación freudiana», El humor (y los humores) en el mundo antiguo 187-202.

Lasa Отхотеко, C.: «Una escritura como lugar de encuentro». Antiguos y modernos 311324.

LEAL, J.: «Duart: Pentesilea: la lluvia de rosas, o del beso al mordisco», Teatro y sociedad en la antigüedad clásica 421-434.

LEAO, D.F.: «Odisseia europeia. O tema de Agamémnon em Jaime Rocha», En recuerdo de Beatriz Rabaza 291-310.

Libros de antigüedades de Andalucía. Edición, introducción y notas de A. Rallo Gruss. Sevilla, Fundación José Manuel Lara, 2009.

LISI BERETERBIDE, F.L.: «La biblioteca virtual del humanismo español y Europa humanistica», Nulla dies sine linea 421-428.

Longo, O.: El universo de los griegos. Actualidad y distancias. Barcelona, El Acantilado, 2009.

LOPETEGUI SEMPERENA, G.: «Antiguos y modernos en el renacimiento cultural del siglo XII», Antiguos y modernos 105-126.

LÓPEZ FÉREZ, J.A.: «Notas sobre los mitos y nombres míticos clásicos en Leopoldo Alas, Clarín», FI 20, 2009, 79-125.

LóPez Férez, J.A.: «Presencia de la Odisea en ¿Por qué corres, Ulises? de Antonio Gala», Fortunatae 20, 2009, 49-70.

LóPEZ FonseCA, A.: «Juan Andrés: una visión ilustrada del teatro grecolatino», Revista de filología alemana, $\mathrm{N}^{\circ}$. Extra 1, 2009, 217-230.

LÓPEZ FONSECA, A.: «Recreaciones clásicas como vehículo de expresión ante la amarga realidad: Orestiada 39 y la Utopía de Albana de A. Martínez Ballesteros», En recuerdo de Beatriz Rabaza 323-338.

LóPEZ FonseCA, A.: «Tradición clásica en el Laurel de Apolo de Lope de Vega», CFCL 29, 2009, 121-144.

LóPez LóPEZ, A.: «Una reescritura feminista de Fedra: Lagartijas, gaviotas y mariposas de MaríaJosé Ragué», En recuerdo de Beatriz Rabaza 311-322.

LóPEZ LóPEZ, M.: «La retórica dramática clásica en Doce hombres sin piedad de Reginald Rose», En recuerdo de Beatriz Rabaza 339-352.

LóPez Pulido, A.: «Electra cruza el Atlántico: a propósito de A Electra le sienta bien el luto de Eugene O'Neill», En recuerdo de Beatriz Rabaza 353-366.

LóPEZ Recio, V.: «El director vanguardista Károlos Kun en su aventura escénica con el drama antiguo», En recuerdo de Beatriz Rabaza 367-380.

López Rodríguez, C.: «El eros lorquiano y su expresión mítica en El Público», En recuerdo de Beatriz Rabaza 381-394.

LÓPEZ-MuÑoz, M.: «La retórica antigua en internet», Pectora mulcet 1323-1336.

LuJÁN, E.: «Jerónimo o `el sagrado nombre': etimologías de los nombres propios españoles», De Homero a Virgilio 143-164.

Magadán Olives, M.T.: «Desmitificar a través de la comicidad: la figura de Hércules en el cine», $E l$ humor (y los humores) en el mundo antiguo 207-223.

MAÑAs NúÑEZ, M.: «Los estudios sobre humanismo renacentista en la Universidad de Extremadura», Nulla dies sine linea 411-420.

Marcelo Martino, L.: «Incómodas investiduras de lo clásico: La Moda (Argentina, siglo XIX)», CFCL 29, 2009, 179-193. 
Martín Rodríguez, A.M.: «Todo lo puede el amor: Harry Potter y los clásicos», Omnia vincit amor 153-182.

Martínez Iniesta, B. - Martínez Bennecker, J.B.: «Dos mitos griegos en Lope y en Calderón», Espéculo: Revista de Estudios Literarios 41, 2009.

Martino, D. DE: «La representación de la violencia trágica en el cine», Teatro y sociedad en la antigüedad clásica 375-386.

MARTino, F. DE: «Antichità e Pubblicità», Antiguos y modernos 17-58.

Martino, F. DE: «»Un' idea un po' per aria»; l' Edipo re di Pier Paolo Pasolini», En recuerdo de Beatriz Rabaza 181-200.

Megino Rodríguez, C.: «Huellas del Aristóteles exotérico en San Agustín», Perfiles de Grecia y Roma 555-566.

Mestre Sanchís, A.: «Humanismo y Humanismos en el siglo XVIII», Perfiles de Grecia y Roma 397-422.

Mimoso-Ruiz, D.: «La trasposition filmique de la tragédie chez Pasolini», En recuerdo de Beatriz Rabaza 395-404.

Miranda Cancela, E.: «Mito y transculturación en Carnaval de Orfeo, de José Milián», En recuerdo de Beatriz Rabaza 405-416.

Molina SÁnchez, M.: «Mito y drama clásicos en la tragedia Ariadna de José Camón Aznar», En recuerdo de Beatriz Rabaza 417-426.

Morais, C.: «A Antígona de António Pedro: liberdades de uma glosa», En recuerdo de Beatriz Rabaza 427-440.

Morenilla Talens, C. - BaÑUls Oller, J.V.: «Orestes de Arcadio López-Casanova y su palinodia», En recuerdo de Beatriz Rabaza 441-456.

Morilla Palacios, A.: «La Atlántida y Macondo: mito y utopía literaria», Studia Historica. Historia Antigua 27, 2009, 129-145.

MüNSTER, R.: «La lucha de poderes en Antigone de Bertolt Brecht», Teatro y sociedad en la Antigüedad Clásica 477-492.

Muñoz García De Iturrospe, M.T.: «La 'Querelle des Femmes' inacabada: de Christine de Pizan a Margaret Atwood», Antiguos y modernos 259-284.

NÁPoli, J.T.: «El debate de Antígona en El Diablo en el cuerpo de Marco Belocchio», En recuerdo de Beatriz Rabaza 457-468.

NAVA CONTRERAs, M.J.: «Amor es un algo sin nombre... Tradición aristotélica y culebrón venezolano», En recuerdo de Beatriz Rabaza 469-478.

NIESSEN, F.: «New testament translations from the Cairo Genizah», CCO 6, 2009, 201-222.

NiETzSChe, F.: De mi vida. El nacimiento de la tragedia. Sobre verdad y mentira en sentido extramoral. Estudio introductorio por G. Cano. Madrid, Gredos, 2009.

NúÑEZ GoNZÁLEZ, J.M.: «Cristóbal de Mesa, traductor», Nulla dies sine linea 265-280.

Ortega Carmona, A.: «La retórica hoy», Pectora mulcet 23-32.

ORTEGA GARRIDO, A.: La materia clásica en las vanguardias españolas. Tesis doctoral. Madrid, Universidad Complutense, 2009.

Paco Serrano, D. De: «Argonautas 2000: interpretación de un mito para el siglo XXI», Myrtia 23, 2008, 427-447.

Paco Serrano, D. De: «Representaciones del teatro griego: la mirada dramática de Theodoros Therzopoulos», En recuerdo de Beatriz Rabaza 201-210.

Pégolo, L. - Cardigni, J. - Meardi, F. - Ramírez, C. - Romero, U.: «De Teseos y Minotauros: el Jardín de piedra de Guillermo Montilla Santillán», En recuerdo de Beatriz Rabaza 479-490.

PePe De SuÁREZ, L.E.A.: «Variantes americanas de la trilogía esquilea», En recuerdo de Beatriz Rabaza 491-498. 
PÉRez AsEnsio, M.: El mito en el teatro cubano contemporáneo. Tesis doctoral. Málaga, Universidad, 2009.

PÉREZ IBÁÑEZ, M.J.: «Presencias clásicas en la Medicina del siglo XVI», Antiguos y modernos 127148.

PÉREZ OROZCO, S.: «Topónimos catalanes de origen griego», ELEA 9, 2009, 431-460.

PiANACCI, R.: «Teatro, mujer y fronteras. Antígona: las voces que incendian el desierto de Perla de la Rosa», En recuerdo de Beatriz Rabaza 499-508.

Picklesimer Pardo, M.L.: «Un caos mitológico: Hércules y el establo de Augias de Friedrich Dürrenmatt», En recuerdo de Beatriz Rabaza 509-522.

PociÑa LóPEZ, A.J.: «Tradición y creación: de Alcestis de Eurípides a Alcesti de Corrado Alvaro», En recuerdo de Beatriz Rabaza 523-528.

PociÑa LóPeZ, A.J.: «Um barco para Ítaca de Manuel Alegre: interpretación revolucionaria de un mito», En recuerdo de Beatriz Rabaza 539-552.

Pons Tovar, M.: «Virtudes y simbología de las piedras preciosas en los Hieroglyphica de Pierio Valeriano», $A M$ 31, 2008, 591-610.

Ragué Arias, M.J.: «El mito griego en el teatro de Raúl Hernández y Rodrigo García», En recuerdo de Beatriz Rabaza 567-576.

REAL TorRes, C.: «La obra de Rodolfo Usigli: un modelo de drama grecolatino en el teatro del siglo XX», En recuerdo de Beatriz, Rabaza 577-586.

Redondo Moyano, E.: «Encomio de personajes femeninos: Elogio de la emperatriz Eusebia de Juliano el Apóstata», Antiguos y modernos 59-80.

Rodríguez Herrera, G.: «La tradición clásica en Valer la pena de Juan Gelman», Myrtia 24, 2009, 307-327.

RoMero MARISCAL, L.P.: «La obscenidad de la violencia y los problemas de la recepción moderna de la tragedia antigua», Teatro y sociedad en la antigüedad clásica 493-504.

Romero Mariscal, L.: «La reivindicación del héroe en Fernando Savater: Último desembarco, una comedia homérica», En recuerdo de Beatriz Rabaza 587-594.

Ruzz SÁnCHEZ, M.: «Cuentos tradicionales en el epigrama neolatino», Myrtia 23, 2008, 343-370.

RYNCK, P. DE: Cómo leer la mitología y la Biblia en la pintura. Traducción de M. Mabres Vicens. Barcelona, Electa, 2009.

Salas Salgado, F.: «Libros clásicos en algunas bibliotecas del Renacimiento en Canarias», Cal.Ren. 8, 2007, 221-246.

Salas Salgado, F.: «Sobre un pasaje de Madrid por dentro de Cristóbal del Hoyo: `... en los salones del engaño, donde se dan los cultos a Medea'», Fortunatae 19, 2008, 193-206.

SALVADOR VentuRA, F.J.: «Las tragedias de Eurípides mediante el cineasta griego M. Cacoyannis», En recuerdo de Beatriz Rabaza 595-606.

SANCHO Rocher, L.: «Teoría moderna y demokratía antigua», Filosofía y democracia en la Grecia antigua 229-262.

SANTANa HenRíQuez, G.: La tradición clásica en la literatura española e hispanoamericana (siglos XVIII-XX). Madrid, Ediciones Clásicas, 2009.

Santana Henríquez, G.: «Et in arcadia ego: la tradición clásica en Luis Cernuda y algunos poetas canarios (Tomás Morales, Saulo Torón, Josefina de la Torre, Pedro Lezcano y los hermanos Padorno)», Ph.Canar.12/13, 2006/2007, 449-496.

SAnZ Mingo, C.A.: «Forcing the Bull into its knees: the Mithraic Strife in Modern Arthuriana», Minerva 22, 2009, 205-215.

Scabuzzo, S.: «Aves argentinas: Salto al cielo de Mauricio Karun», En recuerdo de Beatriz Rabaza 607-618.

SERRANO GARCía, V.: «Nuevas voces de mujer para las heroínas clásicas», En recuerdo de Beatriz Rabaza 619-628. 
SoARes, C.: «O exílio afectivo de Antígona na Perdição de Hélia Correia», En recuerdo de Beatriz Rabaza 645-658.

SousA E SiLva, M.F. DE: «A expressao da maternidade na obra dramática de Hélia Correia», En recuerdo de Beatriz Rabaza 629-644.

STEINER, G.: Antígonas. Una poética y filosofía de la lectura. Traducción de A.L. Bixio. Barcelona, Gedisa, 2009.

TeIXeIRA, C.A.A.: «Um Édipo. Mitodrama fantasmático em um acto de Armando Nascimento Rosa. A face censurada do mito», En recuerdo de Beatriz Rabaza 659-668.

Thompson, D.: «The Ptolemaic library project», Perfiles de Grecia y Roma 843-850.

TolA, E.: «El Orfeo de J. Cocteau: metamorfosis de un mito plurivalente», En recuerdo de Beatriz Rabaza 669-676.

TomAs, I.: «Cocteau et Oedipe: liberté, irrévérence et poésie», En recuerdo de Beatriz Rabaza 677-684.

Tovar Paz, F.J.: «Méliès y la tradición clásica: a propósito de tres de sus filmes cósmicos», $L a$ filología latina. Mil años más 1815-1824.

VALVERDE ABRIL, J.J.: «Eurydice de Jean Anouilh, una reescritura dramatizada del mito y del misterio órfico», En recuerdo de Beatriz Rabaza 685-702.

VALVERde SÁncheZ, M.: «Un mito clásico en el teatro español del siglo XVIII: el Idomeneo de Cienfuegos», Myrtia 23, 2008, 371-388.

Vicente GaRCíA, L.M.: «El peregrino renacentista: a propósito del libro Los jardines del sueño. Polifilo y la mística del Renacimiento», $A M 31,2008,711-728$.

Zecchin De Fasano, G.C.: «El mito de Antígona en la obra de Griselda Gambaro», En recuerdo de Beatriz Rabaza 703-709.

ZoNTA, M.: «Quali scuole filosofiche grece influenzarono il pensiero filosofico ebraico medioevale?», Fuentes clásicas en el judaísmo 117-142.

\section{DiCCIONARIOS. REPERTORIOS. OTROS INSTRUMENTOS}

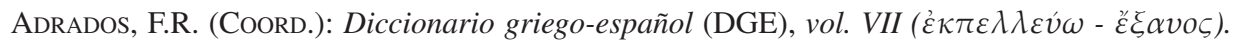
Madrid, Consejo Superior de Investigaciones Científicas, 2009.

Cortés Gabaudan, F. - UReÑa Bracero, J.: «Dicciomed: Diccionario interactivo de helenismos médicos y biológicos», Perfiles de Grecia y Roma 455-462.

Díez Fernández, O. - Giralt, S. - Inclán García-Robés, L. - Pérez Vilarino, Á.: «Chiron, cultura clásica 2.0», Perfiles de Grecia y Roma 463-472.

Fernández Aguado, J.: Preparar la postcrisis. Enseñanzas de la Grecia Clásica. Navarra, Crecento, 2009.

GuTIÉRREZ GonZÁLEZ, R.: «Cui bono? Los verdaderos destinatarios de nuestros diccionarios», Perfiles de Grecia y Roma 235-248.

Lara Peinado, F. - Cabrero, J. - Cordente, F. - Pino, J.A.: Diccionario de instituciones de la antigüedad. Madrid, Cátedra, 2009.

Macías Villalobos, C.: «El empleo de blogs y wikis en el ámbito de la filología clásica», Perfiles de Grecia y Roma 435-452.

Martínez SaURa, F.: Diccionario de mineralogía en el mundo clásico. Castellón, El Lago, 2009.

Peláez Del Rosal, J.: «El Diccionario Griego-Español del Nuevo Testamento (DGENT)», Perfiles de Grecia y Roma 285-296.

PiKaZa Ibarrondo, X.: Diccionario de la Biblia. 1 archivo de Internet. Estella, Verbo Divino, 2009.

RAmOS JuRAdO, E.A. - SANCHO RoYO, A.: Léxico de terminología retórica griega: figuras y tropos. Zaragoza, Pórtico, 2009. 
RodríGUeZ Somolinos, H.: «Publicaciones sobre Filología griega en España (2008)», Epos 25, 2009, 345-378.

\section{DidÁCTICA}

Angelidou, M.: Mites grecs, Educació Primària. Material auxiliar. Barcelona, Vicens-Vives, 2009.

CABANILlas NúÑEZ, C.M.: «Recursos digitales para la enseñanza de las lenguas y la cultura clásicas en Enseñanza Secundaria», Perfiles de Grecia y Roma 425-434.

Carruesco García, J. - González Senmartí, A. - Rodì De Llanza, I. - Tudela Penya, M.: «Una nueva propuesta educativa: máster en papirología (Tarragona, ICAC-URV)», Perfiles de Grecia y Roma 373-378.

Díez Fernández, O. - Giralt, S. - Inclán García-Robés, L. - Pérez Vilarino, Á.: «Chiron, cultura clásica 2.0», Perfiles de Grecia y Roma 463-472.

García Gual, C. - Morales Otal, C. - Lucas De Dios, J.M.: Proyecto La Casa del Saber. Griego. 2 Bachillerato. Madrid, Santillana, 2009.

García Gual, C. - Morales Otal, C. - Lucas De Dios, J.M.: Proyecto La Casa del Saber. Griego. 1 Bachillerato. Biblioteca del profesorado, guía y recursos. Madrid, Santillana, 2009. LÓPEZ-MuÑOZ, M.: «La retórica antigua en internet», Pectora mulcet 1323-1336.

Madrid Navarro, M.: «Didáctica de la Cultura Clásica», Perfiles de Grecia y Roma 329-338.

Martín SÁncheZ, M.A.: «Griego en el Bachillerato», Perfiles de Grecia y Roma 339-348.

ORTEGA, J.M.: «Moodle y la enseñanza de las clásicas en secundaria», EClás.135, 2009, 93-114. 
